\title{
Acute myocardial infarction - progress in primary prevention
}

\author{
Jeremiah Stamler \\ From the Chicago Health Research Foundation and the Department of Medicine, \\ Northwestern University Medical School, Chicago, Illinois, U.S.A.
}

\begin{abstract}
'Mankind's Greatest Epidemic: Heart Disease - Ischaemic Heart Disease, or Coronary Heart Disease, has reached enormous proportions, striking more and more at younger subjects. It will result in coming years in the greatest epidemic mankind has faced unless we are able to reverse the trend by concentrated research into its cause and prevention.

' The Board expressed a wish that countries most affected by cardiovascular diseases increase their efforts both to set up efficient services for control and to carry out more extensive research programmes.'

Executive Board, World Health ORGANIZATION, 27 February 1969.
\end{abstract}

The latest international mortality reports underscore the timeliness of this warning from W.H.O. leadership on the threat arising from the epidemic of coronary heart disease among young and middle-aged adults - particularly in the developed countries (Mortality Statistics, 1967; Stamler, 1969a; Moriyama, Stamler, and Krueger, 1971). Unquestionably this epidemic is taking a worldwide annual toll of hundreds of thousands of persons in the prime of life. In the United States alone, for example - with the second highest mortality rates in the world from premature coronary heart disease - over 165,000 deaths per year are being registered among persons under age 65 , with about three men dying for every woman dying (Mortality Statistics, 1967; Stamler, 1967, I969a; Moriyama et al., I971; U.S. Public Health Service, 1969). The average apparently healthy adult American male has about one chance in five of experiencing a myocardial infarction before age 60 , and about one chance in ten or fifteen of dying from this cause before age 60 (Fig. I) (Stamler, 1967; Moore, 1969; Doyle and Kinch, 1969; Kannel and Doyle, 1971; American Public Health Association, 1957; Doyle, 1963; Paul et al., 1963; Dawber, Kannel, and McNamara, 1964; Keys et al., 1963; Taylor et al., 1962; Chapman and Massey, 1964). The situation is qualitatively similar in many of the other economically developed countries, and for several of those with lower rates the time trend of mortality rates over recent years has been sharply upward (Mortality Statistics, 1967; Stamler, 1969a; Moriyama et al., 1971 ; U.S. Public Health Service, 1969).

Strategy for control of epidemic of premature myocardial infarction and coronary heart disease

An essential prerequisite for an effective effort to control mass disease is a sound strategy. This is one of the major lessons from the whole history of modern public health and preventive medicine. Without a correct strategy it is entirely possible that over the remaining decades of this century many expensive battles will be waged against the myocardial infarction and coronary heart disease epidemic without real progress, that is without significantly reducing morbidity and mortality.

Sound strategy for the control of an epidemic must flow from a detailed, specific analysis of the nature of the disease. Here certain cardinal characteristics of the natural history of myocardial infarction and coronary heart disease must be given central attention. They are well illustrated by the experience of the several U.S. population cohorts whose royear findings were combined in the national co-operative Pooling Project (Fig. I and 2) (Stamler, 1967; Moore, 1969; Doyle and Kinch, 1969; Kannel and Doyle, 1971); American Public Health Association, 1957; Doyle, 1963; Paul et al., 1963; Dawber et al., 1964; Keys et al., 1963; Taylor et al., 1962; Chapman and Massey, 1964). Of 7,594 white men aged 30-59 and free of coronary heart disease at entry, 501 experienced a myocardial infarction or sudden death attributable to coronary heart disease during the first Io years of observation (Fig. 2). Of these incident events, I $23(24.6 \%)$ were sudden deaths, here 


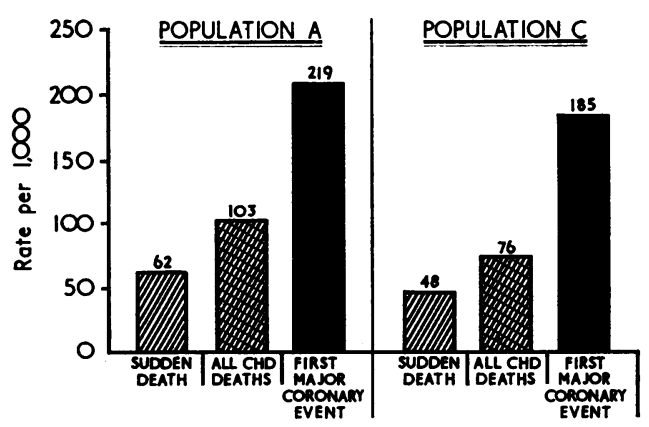

FIG. I Risk of experiencing sudden death, any coronary death, or major coronary event before age 60, U.S. white men age 30-59 at entry. Population A: 7594 men free of definite coronary heart disease at entry. Population $C$ : 6355 men free of any major life-limiting disease, including cardiovascular disease, and with normal electrocardiogram at entry. Tenyear follow-up data of the national co-operative Pooling Project, involving the Albany civil servant, Chicago People's Gas Company, Chicago Western Electric Company, Framingham community, Los Angeles civil servant, and Minneapolis-St. Paul business men studies (Stamler, 1967; Moore, 1969; Doyle and Kinch, 1969; Kannel and Doyle, 1971; American Public Health Association, 1957; Doyle, 1963; Paul et al., 1963; Dawber et al., I964; Keys et al., I963; Taylor et al., I962; Chapman and Massey, 1964). Major coronary events are non-fatal myocardial infarction, fatal myocardial infarction, and sudden death.

defined as death occurring within three hours of observed onset of illness. An additional 42 deaths occurred later in the first acute attack, yielding a total of 165 fatalities - that is, $32 \cdot 9$ per cent of all first episodes terminated fatally.

As has been amply documented recently by several investigators, the majority of deaths from acute myocardial infarction occur so rapidly that time is not available to admit the acutely ill patient to a hospital and an intensive coronary care unit (Fig. 3) (Stamler, 1967 ; Fry, I968; Pantridge, I968; Moss, Wynar, and Goldstein, 1969; Lown, Klein, and Hershberg, 1969). This fact accounts largely for the incapacity of coronary care units to achieve a sizable reduction in overall mortality from acute myocardial infarction. To this must be added the further problem that coronary care units thus far have not been able to cope successfully with the problem of pump failure as a major cause of death in acute myocardial infarction. For the foreseeable future all indications are
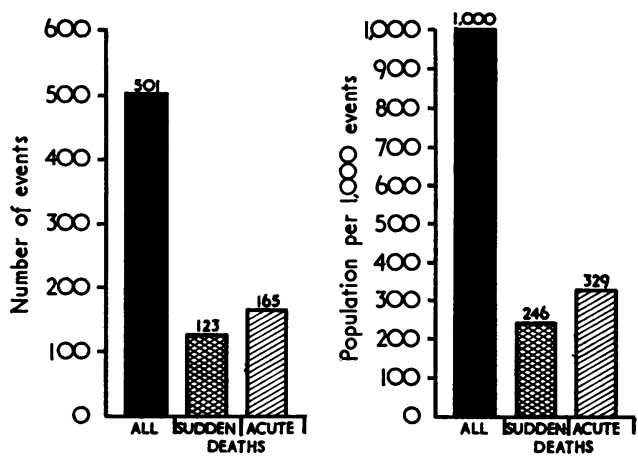

FIG. 2 Sudden death and acute mortality (including sudden death) with first major coronary episodes. Ten-year follow-up data of the Pooling Project (cf. Fig. I), 7594 men age 30-59 at entry, and free of coronary heart disease (Stamler, I967; Moore, 1969; Doyle and Kinch, 1969; Kannel and Doyle, 1971; American Public Health Association, 1957; Doyle, I963; Paul et al., r963; Dawber et al., I964; Keys et al., I963; Taylor et al., I962; Chapman and Massey, 1964).

that only a limited ability exists for overcoming these two crucial problems for persons already ill with acute myocardial infarction.

Moreover, for the approximately 65 per cent of middle-aged persons who recover from an acute first episode of myocardial infarction, likelihood of dying in the next 5 or Io years is much increased, compared with matched persons free of a previous history of

FIG. 3 Hospitalization and mortality with first and recurrent major acute coronary episodes. Cohort of 1329 men age 40-59 in 1958, free of definite coronary heart disease and followed long-term without systematic intervention. People's Gas Company study, Chicago, 1958-68 (Stamler, I967).

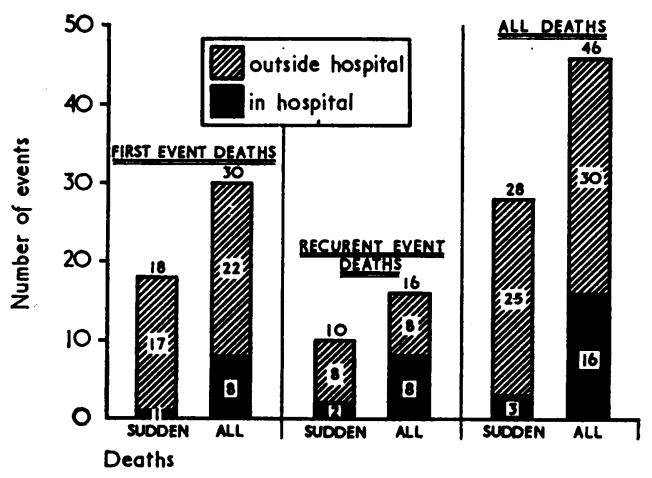


myocardial infarction (Fig. 4) (Stamler, 1967). Excess mortality is due overwhelmingly to recurrent coronary heart disease frequently manifesting itself as sudden death. The national co-operative Coronary Drug Project in the United States has recorded a similar pattern of mortality in its placebo group of 2,788 middle-aged men with previous proved myocardial infarction (Coronary Drug Project Research Group, 1970).

These fundamental facts determine the strategy of the effort to control coronary heart disease. For any disease with this natural history, the main strategic thrust must be primary prevention, that is treatment before illness, or precoronary care, to achieve prevention of first attacks. The prophylactic effort must begin as early in life as possible, and must be continuous over years and decades. Nothing else has the potential for bringing about a sizeable reduction in the epidemic rate of premature myocardial infarction and sudden death - not cardiac resuscitation, highpowered ambulance services, intensive coronary care units, pacemakers, artificial hearts, cardiac transplantations, etc.

Since treatment before illness is the essential strategy for success in the effort to control the coronary epidemic, this paper focuses on this matter and attempts to review the scientific foundations and experiences to date in this area.

Scientific foundations for effort to achieve primary prevention of premature myocardial infarction and coronary heart disease

The underlying disease process in most persons with premature myocardial infarction is severe atherosclerosis of the coronary arteries and its complications. The challenge to medicine and public health inherent in the myocardial infarct epidemic, therefore, is in essence that of preventing and controlling severe atherosclerosis and its complications.

Data have been accumulating for decades on the multiple factors involved in the aetiology of severe atherosclerosis and its sequelae, epidemic myocardial infarction and coronary heart disease. The accumulated findings constitute a firm foundation for rational efforts to prevent the disease.

Clinical findings At a quadrennial World Congress of Cardiology it is particularly appropriate to note that some of the earliest findings, in the 1920 s and 1930s, came from clinical cardiologists. In the years after publication of Herrick's classic paper in 1912, as cardiologists accumulated series of cases of

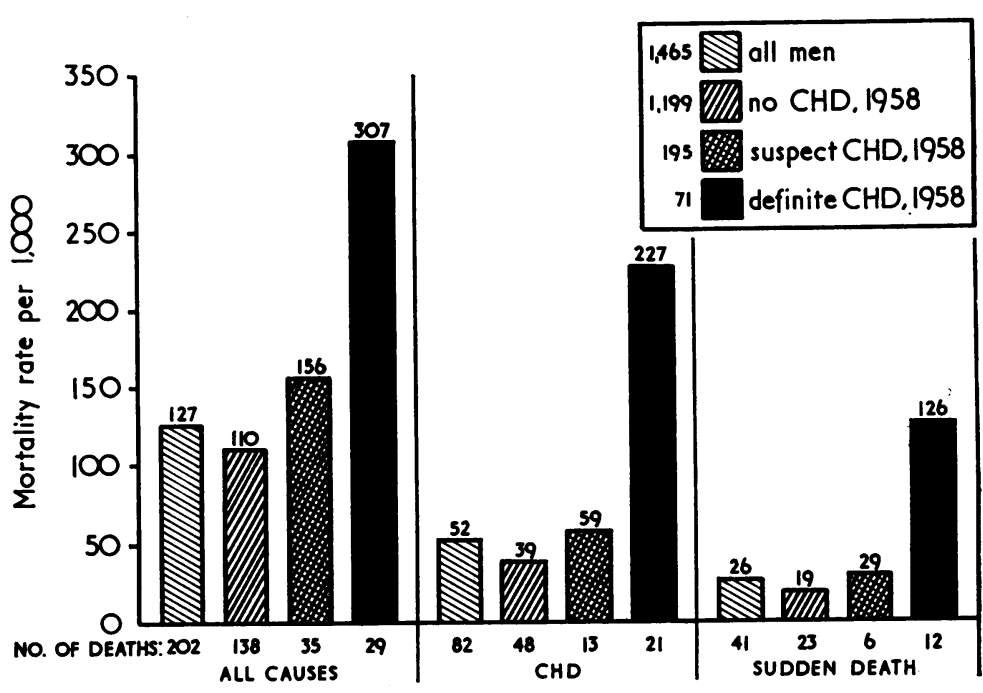

FIG. 4 Coronary heart disease (CHD) status on original examination in 1958 and ten year mortality experience, by cause. Cohort of 1465 men age 40-59 at entry in 1958, People's Gas Company study, Chicago, 1958-68 (Stamler, 1967). All rates age-adjusted by 5-year agegroups to U.S. male population, 1960.

premature myocardial infarction, certain characteristics of the patients became apparent. In particular, it was noted that young and middle-aged adults with myocardial infarction tended frequently to be hypercholesterolaemic, hypertensive, or diabetic, or all three (White, 1944; Katz and Stamler, 1953).

Animal experimental findings From I9Io on, after the initial breakthrough in the experimental production of atherosclerotic lesions by feeding rabbits cholesterol and fat, increasing evidence was amassed on the role of dietary lipid in the production of hypercholesterolaemia and atherosclerosis in animals. Particularly after the second world war, lesions were produced in virtually all species used in the animal research laboratory, mammalian and avian, herbivorous, carnivorous, and omnivorous, including primates (Stamler, 1967; Katz and Stamler, 1953; Katz, Stamler, and Pick, 1958; Constantinides, 1965; Taylor, Patton, and Cox, 1963). Moreover, as has been clearly shown in recent work in various species of monkeys, lesions can be produced by feeding usual table diets of the American type, diets high in cholesterol and saturated fat, whereas they do not supervene when these are modified to reduce intake of cholesterol-fat (Wissler, 1968). In experiments with monkeys, atherosclerotic lesions were induced with only 
moderate increases of serum cholesterol - that is, without gross organ cholesterolosis and xanthomatosis - and they mimicked in their pathology all stages of the human disease, including severe narrowing of coronary arteries with thrombosis, occlusion, and myocardial infarction.

Two other sets of key data have emerged from the animal experimental work: firstly, the repeated demonstration that hypertension accelerates and aggravates the development of lesions when a diet high in cholesterol and fat is fed - that is, when the nutritional-metabolic prerequisites for atherogenesis are present. Secondly, atherosclerotic lesions are to a considerable degree reversible, particularly by restoration of a diet low in cholesterol. This has been repeatedly demonstrated in a wide variety of species, including most recently in primates (Stamler, 1967; Katz and Stamler, 1953; Katz et al., 1958; Armstrong, Warner, and Connor, 1970).

The potential importance of this last finding for the primary preventive effort in man cannot be overestimated. Clearly, for healthy young and middle-aged adults, as yet free of clinical coronary heart disease, the challenge is a relatively modest one; not primarily one of reversing lesions, but - less demanding stopping or at the very least slowing progression of atherogenesis, so that lesions severe enough to produce clinical illness are either completely prevented or significantly delayed. Therefore the demonstration of reversibility in animals, supported by data to the same effect in man (Stamler, 1967; Katz and Stamler, I953; Katz et al., I958; Zelis et al., 1970), is indeed most encouraging.

Epidemiological findings-international comparisons Extensive evidence is available from epidemiological research showing that a confluence of sociocultural circumstances is responsible for the emergence of myocardial infarction and coronary heart disease as the twentieth century epidemic disease of economically advanced countries. One key circumstance is that the mass of the population in affluent countries is able for the first time in history to enjoy a 'rich' diet high in animal products (meats, dairy foods) and is not restricted by harsh economic conditions to cheap starchy foods (bread, potatoes, pasta, oatmeal, cornmeal, etc.). This modern diet - excessive in calories in relation to energy expenditure, high in total fat, saturated fat, cholesterol, sugar leads to high prevalence rates of hyperlipidaemia (hypercholesterolaemia, hypertriglyceridaemia, hyperbeta- and prebeta-lipopro- teinaemia) in the adult population, and sustained hypercholesterolaemic hyperlipidaemia considerably increases risk of premature severe atherosclerotic disease and its clinical sequelae, especially myocardial infarction.

Overwhelming evidence on this matter is available from at least three types of epidemiological research: firstly, there are the repeated analyses making use of data from the U.N.O. Food and Agriculture Organization and World Health Organization. These investigations have consistently shown a close relation between habitual intake of saturated fats, cholesterol, and calories, and mortality from premature coronary heart disease. Differences are especially obvious between populations of highly developed and underdeveloped countries, but they are apparent even from analyses limited to economically advanced countries (Stamler, 1967, 1969a; Moriyama et al., 1971 ; Katz et al., I958). (The international data yield other significant correlations as well for example, between per caput use of cigarettes and coronary heart disease mortality, between number of motor cars per 100 persons and coronary heart disease mortality the multiple aspects of life style in modern industrial society apparently combining to induce the epidemic of premature heart attacks.)

The conclusion concerning the key role of diet is further supported by a second set of evidence, represented particularly by the findings of the International Atherosclerosis Project. This comprehensive study quantitated atherosclerosis of the aorta and coronary arteries at necropsy in over 31,000 persons aged 10-69 dying during $1960-65$ in 15 cities throughout the world (McGill, I968). This massive investigation reported geographic differences in extent and severity of atherosclerosis. Severity of atherosclerotic lesions was found to correlate particularly with population intake of animal fat (saturated fat and cholesterol) and with serum cholesterol level.

Thirdly, research findings on living population groups are consistent with these data from vital statistics and necropsy studies. Especially valuable results are now available from the International Cooperative Study on Cardiovascular Epidemiology, a long-term investigation of 18 population samples in seven countries: Finland, Greece, Italy, Japan, The Netherlands, United States, and Yugoslavia (Keys, 1970). Approximately 12,000 men originally aged $40-59$ have been under investigation for about a decade. On initial examination sizeable differences in prevalence of coronary heart disease were recorded among the population samples. Data on five year incidence and mortality rates from coronary 
heart disease parallel the prevalence data. Differences in coronary heart disease mortality rate were associated with sizeable differences in mortality rate from all causes. Prevalence, incidence, and mortality rates of these populations were highly and significantly correlated particularly with saturated fat intake and serum cholesterol level.

The epidemiological evidence indicates that 'rich' diet is involved in the pathogenesis and aetiology of the myocardial infarction and coronary heart disease epidemic not merely because of its tendency to induce frequent hypercholesterolaemia. This modern diet also contributes significantly (along with low levels of energy expenditure) to the current high prevalence rates of obesity in the economically developed countries, and, largely as a consequence, to high prevalence rates of hypertension, hyperglycaemia, hypertriglyceridaemia and hyperuricaemia, all implicated as important coronary risk factors. Thus diet is related to the myocardial infarction epidemic through several interlinked aetiopathogenic mechanisms.

As already indicated, a second aspect of the twentieth century way of life that has apparently contributed powerfully to the myocardial infarction epidemic has been the development of mass consumption of cigarettes since the first world war. Several sets of data from developed countries, where the nutritionalmetabolic prerequisites for atherogenesis are common, indicate that cigarette smoking adds substantially to risk of premature myocardial infarction (Stamler, 1967, 1969a).

Although the evidence is not entirely airtight and consistent, there is reason to believe that lack of exercise - habitual inactivity at work and leisure - may be another important aspect of the modern mode of life increasing susceptibility to premature myocardial infarction. Finally, data are available showing that the psychocultural stresses and tensions of modern life in highly urbanized, competitive society, and their effects on personality and behaviour, may be playing an important contributory part in the causation of the myocardial infarction epidemic in the developed countries (Stamler, 1967; Katz et al., 1958).

Epidemiological findings: coronary risk factors The basic thesis summarized above is that socioeconomic and sociocultural evolution in the twentieth century has led to a way of life for tens and hundreds of millions in advanced countries that is conducive to widespread premature coronary disease. Repeated reference has been made to coronary risk fac-

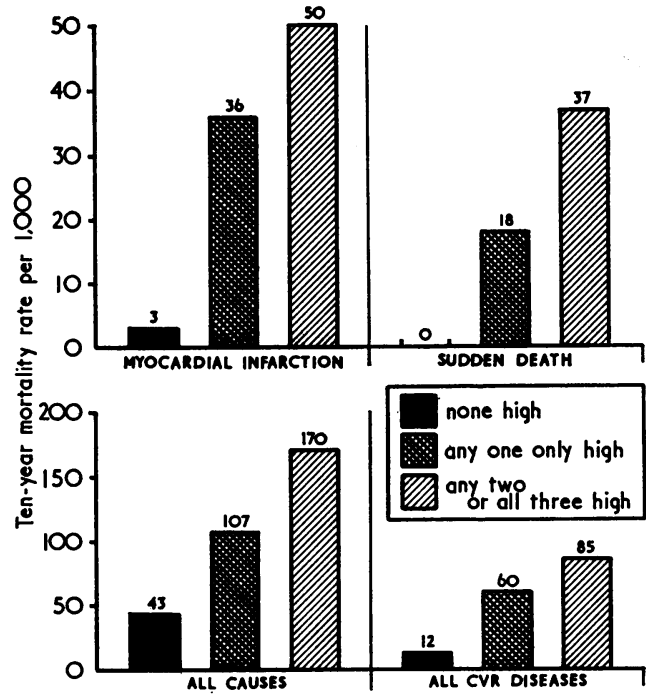

FIG. 5 Coronary risk factors and ten year mortality from myocardial infarction, sudden death, all causes and all cardiovascular renal diseases - People's Gas Company study, Chicago, 1958-1968; the three risk factors based on assessment at first examination in 1958 - are: serum cholesterol $\geqslant 250 \mathrm{mg}$. $/ 100$ ml.; diastolic blood pressure $\geqslant 90 \mathrm{~mm}$. $\mathrm{Hg}$; smoking $\geqslant 10$ cigarettes per day (Stamler, 1967).

tors and their frequent occurrence in the population of the developed nations. Coronary risk factors are those habits, traits, and abnormalities associated with sizeable (100\% or more) increases in susceptibility to premature coronary heart disease - that is, 'rich' diet and diet-dependent hyperlipidaemia, obesity, hyperglycaemia, hypertension, hyperuricaemia; cigarette smoking, impaired vital capacity, sedentary and stressful living; hypothyroidism, renal disease; and positive family history of premature vascular disease (Stamler, 1967; Katz et al., 1958).

Among the variables readily and simply measured in individual patients three stand out as cardinal risk factors in view of their frequency of occurrence, their impact on risk, and their preventability and reversibility: hypercholesterolaemia, hypertension, and cigarette smoking, particularly when present in combination (Fig. 5). Again, these data from our long-term prospective study in the People's Gas Company are typical. Fig. 5 deals with the relation between original status in 1958 with respect to the three cardinal coron- 
ary heart disease risk factors - hypercholesterolaemia, hypertension, and cigarette smoking - and ten-year mortality rates. Men were classified as high or not-high for each of the three factors, using the cutting points specified. Of the entire cohort $(1,329$ middleaged men, free of definite coronary heart disease in 1958 and followed long-term without systematic intervention), 284 (21.4\%) were classified not-high on all three factors. During ten years of follow-up (1958-68) no sudden deaths occurred in this group, only one fatal myocardial infarction, 4 cardiovascular-renal deaths, and 13 deaths from all causes. The ten-year mortality rate from all causes was only $42 \cdot 6$ per 1,000 . The sizeable group of 621 men with only one risk factor (46.8\% of the cohort) exhibited substantially higher mortality rates than the men in the low-risk category with no stigmata. Rates were highest for the group of 420 men (31.7\% of the population) with any two or all three risk factors: 17 times higher than the lowrisk group for myocardial infarction, four times higher for all causes.

Of these 420 very high-risk men, $67(5.0 \%$ of the entire cohort) manifested all three risk factors. Their ten-year age-adjusted mortality rate from myocardial infarction was 63.4 per I, 000 , more than 20 times that of the lowrisk group. Their death rate from all causes was 225.9 per I,000, almost six times that of the low-risk group.

The inference for prevention from the accumulated clinical, animal-experimental, and epidemiological findings is almost selfevident. Major possibilities exist for the prophylaxis of premature myocardial infarction and coronary heart disease through a long-term public health and preventive medicine endeavour, involving the entire population, aiming at the elimination of the harmful living habits generating mass coronary proneness, particularly the harmful habits of 'rich' diet, cigarette smoking, and sedentary living. Furthermore, special possibilities exist for immediate successes in prevention by pinpointed, concentrated efforts to detect very high-risk young and middle-aged adults, and to institute effective long-term measures to alter the habits and traits contributing to their marked susceptibility (Stamler et al., 1969a; Inter-Society Commission on Heart Disease Resources, I970).

As noted, an impressive mass of inferential evidence supports these conclusions about primary prevention. One remaining important question is: What body of direct experience is there concerning the possibility and practicality of this prophylactic approach ?
Research studies on primary prevention of myocardial infarction and coronary heart disease

The first prospective data demonstrating relationships between coronary heart disease risk and such traits as hypercholesterolaemia and hypertension were presented in October, I956 and published the following April (American Public Health Association, 1957). That report, together with the clinical, pathological, animal-experimental, and epidemiological data then available from other sources, undoubtedly was a key factor at that time stimulating four research groups to go beyond descriptive-analytical investigations to experimental studies - that is, field trials on primary prevention. The remainder of this paper reviews the findings in these 'first generation' studies, with emphasis on their long-term data on ability to achieve primary prevention (Jolliffe, Rinzler, and Archer, 1962; Rinzler, I968; Turpeinen et al., 1960, I968; Dayton et al., 1962, 1969; Stamler, 1960, 1969b; Stamler et al., 1969b). No summary of the results from the National Diet-Heart Study is included, since this investigation was a feasibility study with findings reported in detail; it yielded no data on the crucial issue of prevention of myocardial infarction and coronary heart disease (National Diet-Heart Study Research Group, 1968). Similarly, no information is presented here on three longterm primary prevention trials currently in progress, since no data are as yet available from them on myocardial infarction and coronary heart disease morbidity and mortality. These are a diet modification trial in Minnesota mental hospitals, a cigarettesmoking control trial in British civil servants, and a co-operative trial of the lipid-lowering drug clofibrate proceeding in Edinburgh, Budapest and Prague (I. Frantz, personal communication, 1970; G. Rose, personal communication, 1970; M. Oliver, personal communication, 1970; Oliver, 1970).

The New York Anti-Coronary Club study The New York Anti-Coronary Club study, initiated in 1957, has enrolled 941 men in its experimental group. They were aged 40-59 at entry and met medical criteria for a primary prevention study - that is, they were free of clinical coronary heart disease (Jolliffe et al., 1962; Rinzler, I968). After demonstration that dietary change could be satisfactorily effected in free-living volunteers, a comparison group of 457 men aged 40-59 was recruited, beginning in 1959. The two groups were similar in serum cholesterol levels; the experimental group had a higher 
proportion of men with obesity and hypertension at entry, as well as combinations of these three risk factors. Available data also indicate that the groups were comparable with respect to cigarette smoking status at entry, and change in this risk factor during participation in the study. Differences in demographic composition of the two populations are regarded as insignificant in terms of risk of clinical myocardial infarction and coronary heart disease.

The study has dealt exclusively with nutritional habits of the experimental group for the purpose of reducing serum cholesterol levels, as well as weight in obese volunteers. Its Prudent Diet eliminated or de-emphasized butter, whole milk, cheeses, ordinary margarines, hydrogenated shortenings, beef, pork, lamb and eggs, and replaced these with vegetable oils, fish, nuts, and leaner meats (for example, poultry and veal). In this way a significant decrease in intake of saturated fats and cholesterol was effected, as well as an increase in intake of polyunsaturated fats. During the initial period of weight reduction the daily diet averaged about 1,600 calories and contained 19 per cent of total calories as fat. Subsequently the diet was composed of 33 per cent of calories from fat (equally divided among saturates, monounsaturates, and polyunsaturates), 48 per cent from carbohydrate and 19 per cent from protein. In contrast, diet composition of the volunteers at entry averaged 40 per cent of total calories from fat (46\% saturates, $40 \%$ monounsaturates, $14 \%$ polyunsaturates).

As planned, moderate weight reduction was accomplished. Serum cholesterol fell initially about $30 \mathrm{mg}$./100 ml., from a mean control level of 260 . This decrease was essentially maintained long-term in active participants. Serum triglycerides also fell. No significant sustained decline of serum lipids occurred in the comparison group.

The most recently published analysis of long-term effects on incidence of myocardial infarction and coronary heart disease, as of 30 November 1967, indicated that of the $94 \mathrm{I}$ volunteers in the experimental group, 532 had become inactive (Rinzler, I968). Altogether the 94I men had accumulated 3,954 person-years of experience as active participants; the 532 men who lapsed into inactive status had accrued 3,207 person-years of experience in that circumstance. The control group had accumulated 3,122 person-years of experience. Confirmed new events of myocardial infarction and coronary heart disease were 17,24 , and 32 in these three categories, respectively, and incidence rates were $4.3,7 \cdot 5$,

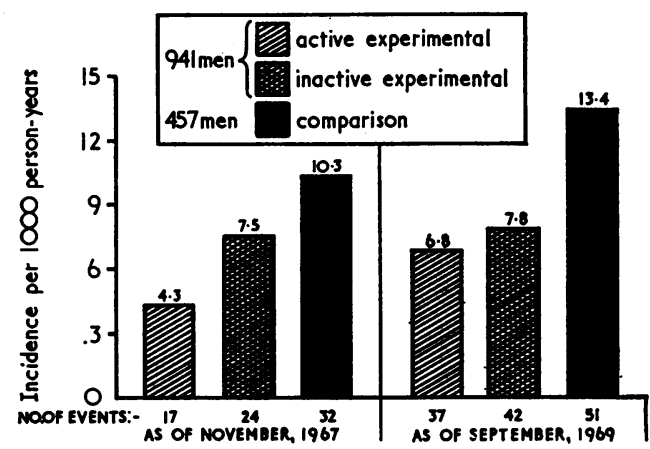

FIG. 6 Coronary heart disease incidence in the active experimental, inactive experimental, and comparison groups of the New York AntiCoronary Club study participants, men aged 40-59 at entry and free of clinical coronary heart disease (Rinzler, 1968; M. Archer, personal communication, 1970). Rates for the experimental group age-adjusted to comparison group.

and 10.3 per 1,000 person-years (Fig. 6) (Rinzler, 1968). This incidence rate of the active experimental group was significantly lower than that of the control group.

These data have recently been updated to September 1969. Events of coronary heart disease and myocardial infarction in the three categories, active experimental, inactive experimental, and control, numbered 37,42 , and 51 , respectively, and incidence rates (age-adjusted to the control group) $6.8,7.8$, and 13.4 per I,000 person-years (Fig. 6) (M. Archer, personal communication, 1970).

No data have been reported on mortality from coronary disease or all causes in these three groups.

The Finnish mental hospital study The Finnish mental hospital study was started in 1958 in two hospitals in Helsinki, designated as Hospital $\mathbf{N}$ and Hospital $\mathrm{K}$, respectively (Turpeinen et al., 1960, 1968). The initial numbers of subjects were 234 and 172 men age 34-64 in Hospitals $N$ and $K$, respectively. Mean ages were $5 \mathrm{I} \cdot 4$ and $5 \mathrm{I} \cdot \mathrm{I}$ years. Average annual loss of subjects was about 16 and 13 per cent, respectively. In order to keep the number of participants approximately constant, new men were added annually to the groups. A sizeable proportion of patients -35 and 44 per cent in Hospitals $N$ and $K$, respectively - remained in the study for its entire first phase, from I January 1959 to 28 February I965 (see below). Prevalence rates of hypertension and cigarette smoking were 
generally comparable in the patient groups of the two hospitals.

The designated patients in Hospital $\mathrm{N}$ served as the experimental group during the first phase, and those in Hospital $\mathrm{K}$ served as the control. In the former hospital the diet was changed so that a large part of milk fat was replaced by soybean oil, given chiefly as filled milk and soft margarine. Use of fat meats was discouraged, whereas generous use of vegetable oils in cooking was recommended for Hospital N. In Hospital $\mathrm{K}$ no dietary change was instituted during the first six years of the study. Thereafter, in 1965, Hospital N returned to its original prestudy diet, and Hospital $\mathrm{K}$ was placed on the experimental diet. Thus the roles of the hospitals in the experimental design were reversed.

Before the start of the experiment the diets in both hospitals were fairly similar in fat composition, with large quantities of saturated fat, derived mainly from whole milk and butter. The total fat content was 3I-36 per cent of calories, with milk fat contributing about I7 per cent of calories. The dietary change in Hospital $\mathrm{N}$ cut the intake of saturated fats to one-half its original level and increased ingestion of polyunsaturates threefold. No change in per cent of calories from total fat occurred in the patients in the experimental hospital.

Dietary cholesterol intake was lower at baseline in Hospital $\mathrm{N}$ than $\mathrm{K}$, because of a much smaller consumption of eggs. Institution of the experimental regimen in Hospital $N$, with nearly total removal of milk fat, brought about a further reduction in dietary cholesterol content. Thus at baseline the daily intakes were 368 and $540 \mathrm{mg}$. for subjects in Hospital $N$ and $K$, respectively. Thereafter they remain unchanged for Hospital $K$, but were in the range $186-27 \mathrm{Img}$. for Hospital N.

At baseline the mean serum cholesterol level was lower for the men in Hospital $N$ than in Hospital $\mathrm{K}$, although not statistically significantly so $(235.8$ against $252.6 \mathrm{mg}$./100 ml.). Institution of the experimental diet in Hospital $\mathrm{N}$ was associated with a significant fall in serum cholesterol of $21 \cdot 2 \mathrm{mg}$. $/ 100 \mathrm{ml}$. and this change persisted throughout the period 1959-65 until the aforementioned dietary crossover. The differential between the two hospitals was greater for serum cholesterol than for triglyceride.

With mental hospital patients as the participants, this study relied chiefly upon serial electrocardiography to reveal new manifestations of nonfatal coronary heart disease. In the first phase of the study incidence of new electrocardiographic patterns attributed to

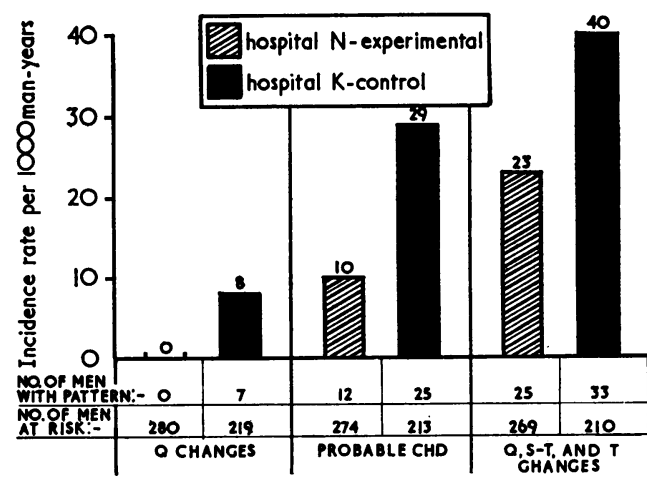

FIG. 7 Incidence of electrocardiographic patterns attributable to coronary heart disease, men age 34-64 at entry, Finnish mental hospital study, 1959-65 (Turpeinen et al., 1968).

coronary heart disease was, by all criteria used, much, and significantly, lower in experimental Hospital N compared with the control Hospital K (Fig. 7) (Turpeinen et al., 1968). The 280 and 219 patients of Hospitals $\mathrm{N}$ and $\mathrm{K}$, respectively, accrued $\mathrm{I}, 208$ and 890 manyears at risk, respectively, with a mean period of risk per man of 4.3 and $4 \cdot I$ years, respectively. During this time no men in Hospital N and seven in Hospital $\mathrm{K}$ developed major abnormal $Q$ waves on the electrocardiogram, with incidence rates of nil and 7.9 per 1,000 man-years, respectively. The difference was significant $(p<0.01)$. A corresponding difference in rates for mortality from all causes and from coronary heart disease was recorded, again in favour of the patients in Hospital N. However, the difference in coronary mortality rate was not statistically significant. When overall incidence of coronary heart disease (nonfatal plus fatal) was calculated by combining electrocardiographic and mortality evidence, a definitely lower total incidence for the experimental hospital was found and the difference was highly significant statistically. Annual incidence rates per thousand were 14.4 and 33.0 in the experimental and control groups, respectively.

At present this study is still in progress in its second phase, after reversal of diets, so that Hospital $\mathrm{K}$ is currently serving as experimental and Hospital $\mathrm{N}$ as control institution. With reversal of diet patterns corresponding crossover of serum cholesterol levels has occurred, as anticipated. The average difference between the hospitals has been about $35 \mathrm{mg}$./100 ml. during this second phase. Incidence of electrocardiographic patterns indicative of coronary heart disease has been 
smaller in the experimental hospital. However, number of events as of May 1970 is not of a magnitude to record a statistically significant difference between the institutions. Similarly, no definitive results are available as yet concerning patterns of mortality from coronary heart disease and all causes (O. Turpeinen, personal communication, 1970).

The Los Angeles Veterans Administration domiciliary study The Los Angeles Veterans Administration domiciliary study, initiated in 1959 and completed in early 1967 , involved a total of 590 men originally aged 55 and over (median age approximately 65 years), free of definite or possible complications of atherosclerosis at entry (Dayton et al., 1962, 1969). These men were randomly assigned to experimental and control groups. The two groups were apparently indistinguishable at entry in almost all of the multiple characteristics evaluated. They were fed from two different cafeteria lines in their Veterans Administration facility of residence, thus permitting conduct of the trial on a double-blind basis. The experimental regimen was concerned solely with altering composition of the diet to reduce saturated fat and cholesterol intake and increase polyunsaturated fat intake. An effort was made to achieve substitution of unsaturated for saturated fat to the maximum degree compatible with palatability. Iodine value of ingested fat was 53.5 and 102.4 in the control and experimental groups respectively, and cholesterol intake averaged 653 and 365 mg. per day. No attempt was made to alter total daily calories or percentage of calories from total fat, protein or carbohydrate. Daily caloric intake averaged approximately 2,500 calories, with total fat of III g. and $108 \mathrm{~g}$. in the control and experimental groups representing 40 and 39 per cent of total calories, respectively. No effort was made to reduce weight of obese participants in the experimental group, or to control hypertension or eliminate cigarette smoking.

Overall adherence, expressed as percentage of total possible meals taken from introduction into the study to termination of the study, averaged 56 and 49 per cent for the control and experimental groups, respectively. The experimental diet induced a prompt drop in serum cholesterol. This persisted, and amounted long-term to a 12.7 per cent decline from the starting level. The resultant difference between experimental and control groups was also sustained.

'Hard' endpoints - used to evaluate effects over eight years of the experimental diet included myocardial infarction, sudden death

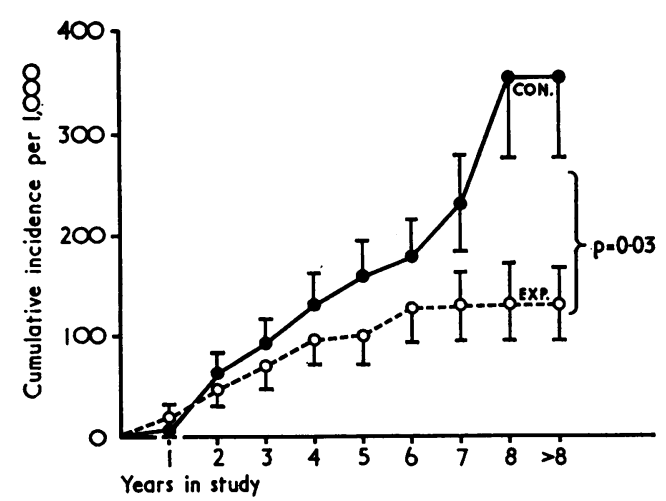

FIG. 8 Cumulative incidence for 'hard' end points - myocardial infarction, sudden death due to coronary heart disease, cerebral infarction, ruptured aneurysm, amputation; 590 men free at entry of atherosclerotic disease. Los Angeles Veterans Administration Domiciliary Study, 1959-67. Points are plotted as cumulative incidence rates \pm standard error, plotted in one direction only in some cases, or omitted for clarity. The $p$ value refers to comparison of the entire curves. CON is the control group; EXP, the experimental group (Dayton et al., 1969).

due to coronary heart disease, definite cerebral infarction, ruptured aneurysm, amputation, and a miscellaneous group of causes definitely attributable to underlying atherosclerotic disease. Comparison of control and experimental groups by life table analysis over the eight years of the study revealed a significantly lower cumulative incidence rate for all 'hard' endpoints for the experimental group men without pre-existing signs of atherosclerotic disease (Fig. 8) (Dayton et al., 1969). (In accordance with the focus of this presentation on primary prevention no effort is made here to review the positive findings of the Los Angeles study on men with evidence of atherosclerotic disease at entry.) With stratification by median age $(65.5$ years) and serum cholesterol level (233 mg./ $100 \mathrm{ml}$.) at entry, respectively, the published data indicate that clearcut and significant differences between experimental and control groups were recorded for younger (rather than for older) men, and for men with higher (rather than with lower) serum cholesterol levels. The statistically significant differences in incidence of major atherosclerotic events could not be accounted for by any confounding variables, including cigarette smoking status (Dayton and Pearce, 1970). 
The findings with respect to fatal atherosclerotic events paralleled those for overall incidence of 'hard' endpoints, but the $p$ value was 0.15 - that is, higher than the conventional 0.05 level for statistical significance.

No data on total mortality are contained in the final report for the cohort of men free of evidence of atherosclerotic disease at entry. However, the published monograph does contain evidence consistent with the inference that total mortality rates were similar, and not lower in the men consuming the fatmodified diet, because of an excess of carcinoma deaths in the experimental group during the last years of the study.

The Chicago Coronary Prevention Evaluation Programme The Chicago Coronary Prevention Evaluation Programme (CPEP) was designed by our group in 1957, and launched in the following year. Intake of participants continued from I958 to mid-I968 (Stamler, 1960, 1967, 1969b; Stamler et al., 1969b). The final cohort numbers 519 coronary-prone male volunteers, originally aged 40-59 and free of clinical coronary heart disease and other life limiting diseases. Criteria for the high risk designation generally included combinations of hypercholesterolaemia, hypertension, cigarette smoking, overweight, and fixed minor $T$ wave abnormalities on the baseline resting electrocardiogram (low voltage, flat or diphasic $\mathrm{T}$ waves) (see Fig. 13 and 14 ). In addition to these criteria, a few men with severe hypercholesterolaemia, in the range $325 \mathrm{mg}$./100 ml. or greater, were accepted based on this risk factor alone.

Unlike the three foregoing studies, dealing exclusively with diet, the Coronary Prevention Evaluation Programme undertook to assess combined nutritional-hygienic means for the correction of five coronary risk factors: hypercholesterolaemia, obesity, hypertension, cigarette smoking, and physical inactivity. The deliberate decision was made to intervene against all these, to test the general hypothesis that primary prevention of myocardial infarction and coronary heart disease in high-risk middle-aged men could be achieved by controlling several major coronary risk factors. A nutritional-hygienic approach was from the beginning the cornerstone of the effort, in keeping with the basic theoretical conclusion that the coronary heart disease epidemic is a result of socioeconomic evolution leading frequently to a pattern of faulty living habits that act synergistically to intensify risk. The hypothesis, then, was that the key to prevention must be the establishment and maintenance of sound living habits, leading to correc- tion and control of coronary risk factors. In this context drugs were viewed only as adjuvant tools by and large, not of central and decisive importance for mass prevention of disease. Therefore the control of hypertension in the Coronary Preventive Evaluation Programme investigation was limited to nutri-

FIG. 9 (A): nutrient composition of diet, Coronary Prevention Evaluation Programme cohort, before (control) and during (all diet data) participation in study. (B): percentage of total calories from major food sources before and during participation in study; data collected during early months in study by seven-day food record method (Stamler, 1967).
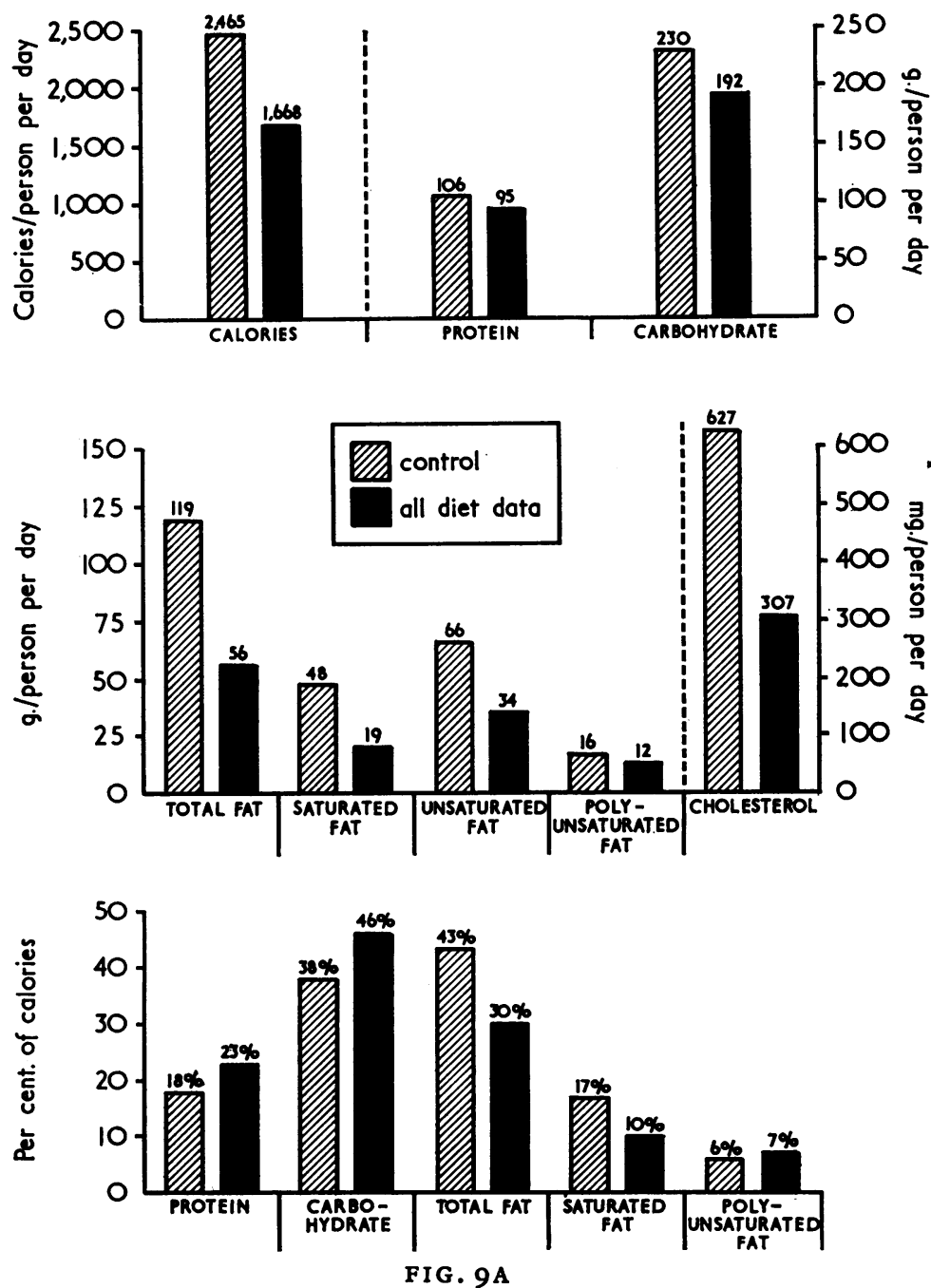

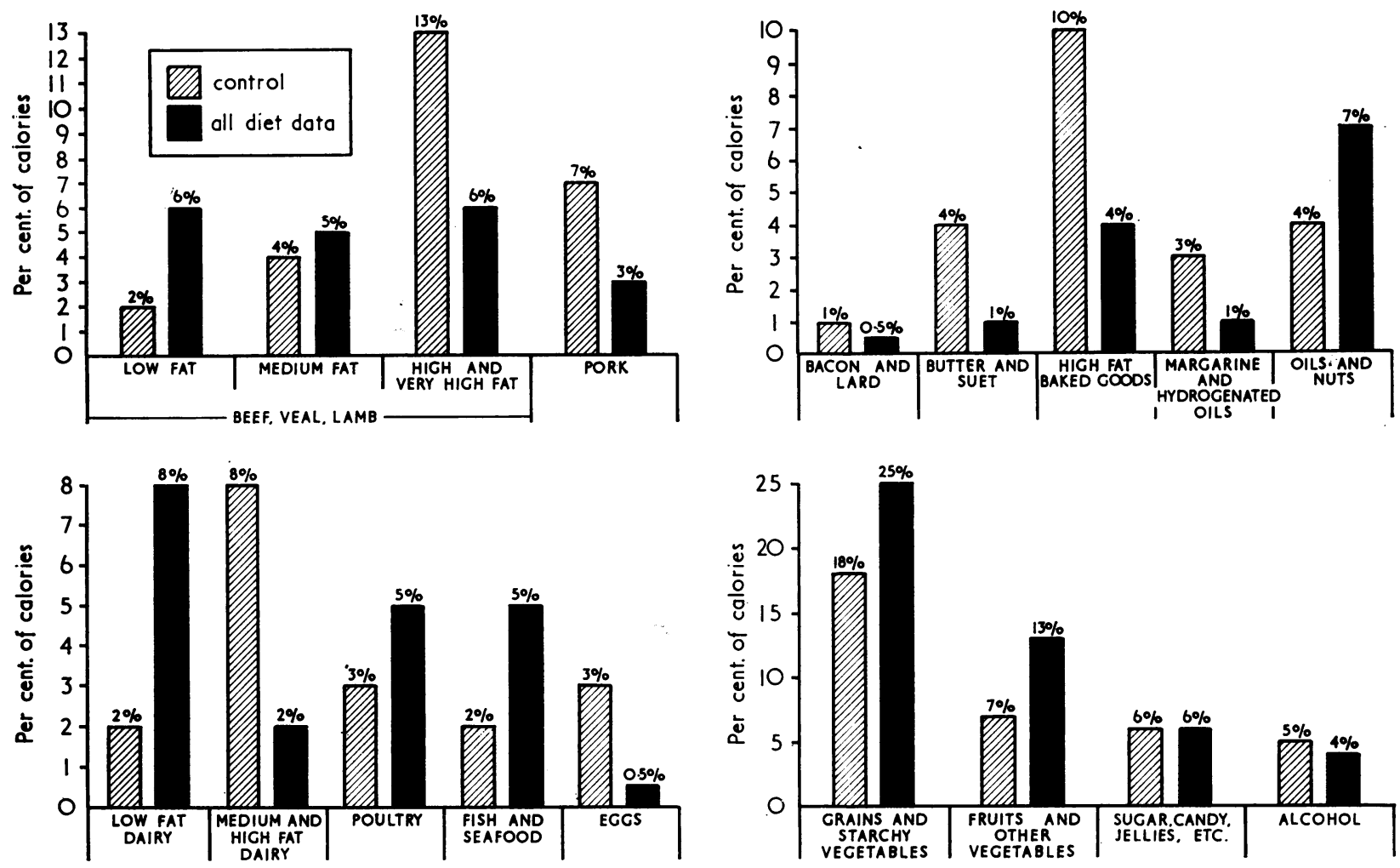

FIG. 9B

tional means, principally correction of overweight and moderate salt restriction - and any indicated drug therapy was left to the judgement of the participant's personal physician.

Modification of nutritional habits has been the primary and major effort of the programme, for the control chiefly of hyperlipidaemia and obesity, but also for its role in the management of hypertension. The cornerstone of the nutritional programme is to work for a permanent change in eating habits in order to effect and maintain correction of dietrelated risk factors. The diets are moderate in calories, moderate (not low) in total fat and carbohydrate, low in saturated fat, cholesterol and simple sugars, moderate (not high) in polyunsaturated fat (Fig. 9). Changes in nutrient intake were accomplished by altering habits with regard to ingestion of all five major sources of saturated fat and cholesterol in the U.S. diet: meats, dairy products, commercial baked goods, eggs, and table and cooking fats (Fig. 9). A systematic and sustained process of education and motivation was carried out for this purpose (Stamler, 1967).
During initial months in the study attention of participants and their wives was focused on the effort to change eating habits. Attention was turned only during subsequent months to correction of cigarette smoking and sedentary living habits, and the data suggest that the programme has been less successful in controlling these risk factors than those related to nutrition (see below).

Recruitment of middle-aged healthy male volunteers for this study was readily accomplished, principally through the co-operation of several industrial firms in Chicago. A key concern throughout has been the maintenance of maximal effective long-term participation. All men were asked to volunteer for a period of at least five years. The original protocol of the study set a goal of keeping the five-year dropout rate under 50 per cent, since it was appreciated that failure to attain this minimum objective would negate any possibility of an effective field trial.

Each year the programme 'closes book' as of 31 March, and makes a detailed evaluation of the status of all participants. In this way, no men have been lost to follow-up. Data as 
of 3I March I970 reveal overall cumulative dropout rates (calculated by life table method) (Cutler and Ederer, 1958) considerably less than 50 per cent at five years - actually only 22.6 per cent, with a seven-year dropout rate of only $37 \cdot 1$ per cent (Fig. IO). Dropout rate has been conspicuously higher, almost double, in men with the cigarette smoking habit at entry, compared with non-cigarette smokers (see below).

As a result of the recommended nutritional alterations, men in the Coronary Prevention Evaluation Programme experienced a highly significant decline in weight, serum cholesterol, and triglycerides. Detailed findings have recently been reported elsewhere (Stamler, 1969b; Stamler et al., 1969b). In brief, once weight and serum lipids were reduced, changes were generally maintained for years by active participants. Thus for hypercholesterolaemic men in the programme for at least five years, fall in serum cholesterol averaged 15 per cent, from a control value of $307 \mathrm{mg}$./ $100 \mathrm{ml}$. to 260 (range over the five years 247-269). Weight reduction averaged about 7 per cent. In association with this change in caloric balance and the alteration in dietary composition, serum triglycerides of hypertriglyceridaemic men fell by approximately 30 per cent from a baseline level of 213 to $149 \mathrm{mg}$./100 ml.

These reductions in serum lipids were effected by Coronary Prevention Evaluation Programme nutritional recommendations without utilizing jiggers of oil, special oil allotments, or fat-modified foods. Such dietary measures were not required to achieve the desired alterations in quantity and quality of ingested nutrients. Ordinary foodstuffs generally sufficed, particularly since the main emphasis for most participants was not on achieving high intake of unsaturated and polyunsaturated oils. Rather it was on assuring a low saturated fat, low cholesterol, moderate calorie intake, with consumption of polyunsaturated fats in moderate amounts as adjuvant. This nutritional emphasis of the Chicago Programme was clearly somewhat different from that of the Helsinki and Los Angeles studies, with their major efforts to increase considerably the intake of polyunsaturates. The Chicago programme approach has been premised on the mass experience of populations with low serum cholesterol levels, and low rates of mortality from coronary heart disease and all causes among middle-aged persons. In all these populations - for example, Dalmatian, Greek, Japanese, southern Italian - intake of saturated fat and cholesterol is much lower than among Americans, but polyunsaturated fat intake does not differ. In particu- lar, it is not higher; in fact in some populations (for example Japanese) it is lower. And no population habitually consumes more than to per cent of calories from polyunsaturates (Stamler, 1967, I969a; Katz et al., 1958; Keys, 1970; National Diet-Heart Study Research Group, 1968). No clear-cut population or experimental evidence is extant on the lifespan safety of diets very high in polyunsaturates (for example, $15 \%$ or more of total calories) and the findings of the Los Angeles study pose questions in this area (Dayton et al., 1969). There is no real need for such diets (Stamler, 1967, Katz et al., I958; Keys, 1970; National Diet-Heart Study Research Group, 1968), and therefore no real reason to 'push hard' for them. They are best avoided. The sound approach is to emphasize control of saturated fat, cholesterol and calorie intake.

The Chicago nutritional effort was associated with a significant sustained fall in blood pressure of hypertensive men, from a baseline mean level of ror $\mathrm{mm}$. $\mathrm{Hg}$ to an average of 92 over a five-year period of active participation (range 9I-94). Almost certainly this was largely a byproduct of control of overweight in these obese hypertensive men.

Of the 519 participants, I9I were cigarette smokers at entry. As already indicated, dropout rate was sizeable in this group (Fig. IO). Of the II6 cigarette smokers at entry who were still active participants in the programme as of 31 March 1970, only $43(37 \cdot 1 \%)$ met study criteria for effective cessation of cigarette smoking - no consumption of cigarettes for at least one year. Thus, as already noted, the relatively limited endeavours to cope with this

FIG. Io Cumulative dropout rate, calculated by life table method, Coronary Prevention Evaluation Programme men, stratified by cigarette smoking status at entry; data as of 31 March 1970.

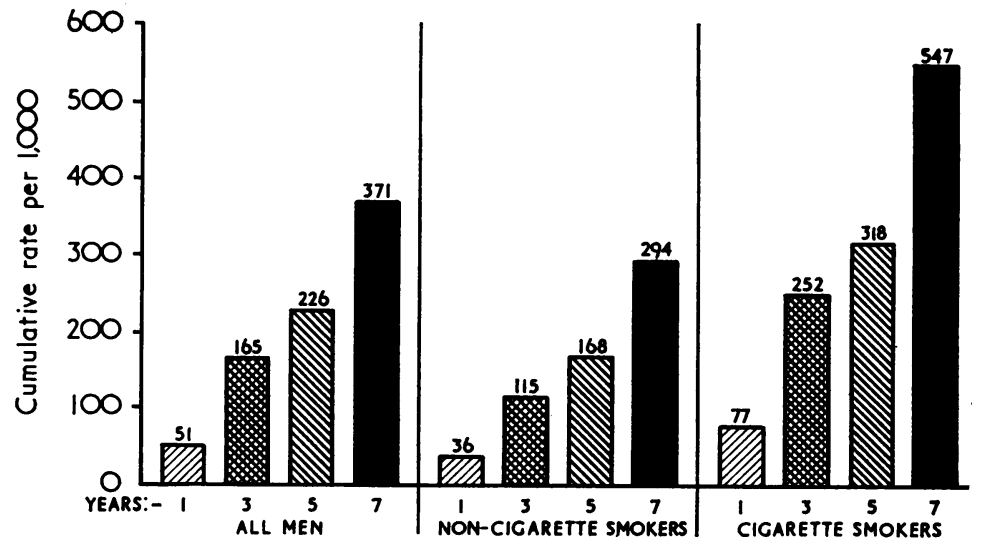


habit, compared with the major attention to changing nutritional habits, achieved only limited success. This experience is of considerable relevance in relation to the longterm preventive goals of the programme (see below).

With respect to exercise, interview data suggest that a majority of active participants have made a transition from an essentially sedentary living habit to one of light activity. Fitness evaluation by quantitative graded exercise tests on a subgroup of men entering the study in $1967-8$ gives evidence of a modest improvement in fitness (Fig. II).

Mortality is the decisive endpoint under assessment in this programme. The mortality experience of Coronary Prevention Evaluation Programme participants is being evaluated in comparison with findings for men in the national co-operative Pooling Project, selected from its latest data tape to meet the entry criteria of the Coronary Prevention Evaluation Programme with respect to age, and medical and risk factor findings. The mortality analysis presented below deals with seven year followup for the cohort, as of 31 March 1970, and corresponding data from the Pooling Project (Stamler, 1967; Moore, 1969; Doyle and Kinch, 1969; Kannel and Doyle, 197I; American Public Health Association, 1957; Doyle, 1963; Paul et al., 1963; Dawber et al., I964; Keys et al., 1963; Taylor et al., 1962; Chapman and Massey, 1964). Of the several thousand men with data in the Pooling Project, 2,916 were identified who met the age, and medical and risk factor criteria. Age-adjusted semi-annual and cumulative mortality rates were calculated by the life table method (Cutler and Ederer, 1958) for the first seven years of experience for the cohorts of Coronary Prevention and Pooling Project men, and appropriate subgroups (as indicated below). As of 31 March 1970, the mean duration of followup for the Coronary Prevention Evaluation Programme cohort was almost five years. Of the 519 men, $244(47.0 \%)$ had completed five years of participation and 16I (31.0\%) had completed seven years of participation. Since numbers of Coronary Prevention Evaluation Programme men at risk are small beyond the seventh year of follow-up, data are presented only through this period.

Overall data on mortality are presented in Fig. I2 for seven years of follow-up. For the key endpoints, total mortality, coronary heart disease mortality, and sudden death, the seven year cumulative mortality rates indicate a trend in favour of the Coronary Prevention Evaluation participants, compared with the Pooling Project men. This is particularly true

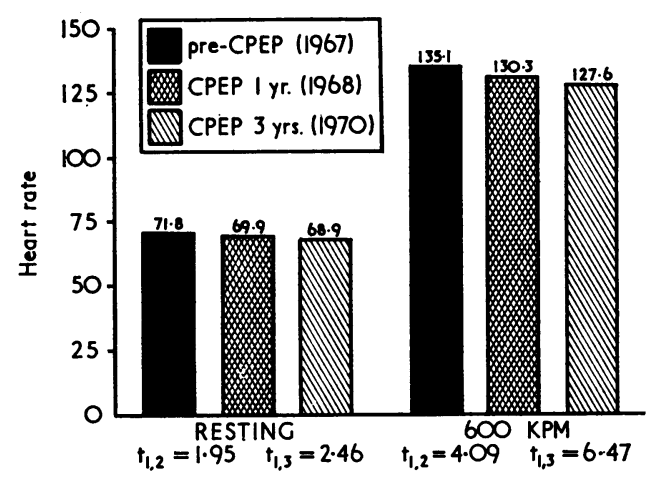

FI G. II Effects of Coronary Prevention Evaluation Programme on cardiopulmonary fitness, measured by standardized test on bicycle ergometer; subgroup of 67 men taken into study in 1967 and submitted to fitness test during control period; correlated t test to assess significance of differences.

for the 377 continuing active participants (non-dropouts) in the Coronary Prevention Evaluation Programme. For this latter group, total mortality at seven years is 46.0 per cent lower compared with the experience of the 2,916 Pooling Project men; coronary heart disease mortality and sudden death mortality are 75.0 and 86.7 per cent lower, respectively. For all 519 Coronary Prevention men (continuing participants and dropouts combined),

FIG. 12 Seven-year cumulative mortality rates, high-risk disease-free men age 40-59 at entry, Pooling Project and Coronary Prevention Evaluation Programme cohorts. Coronary Prevention Evaluation Programme men stratified by dropout status, as of 31 March 1970; all rates calculated by life table method, with age-adjustment by 5-year age groups to U.S. male population, 1960 .

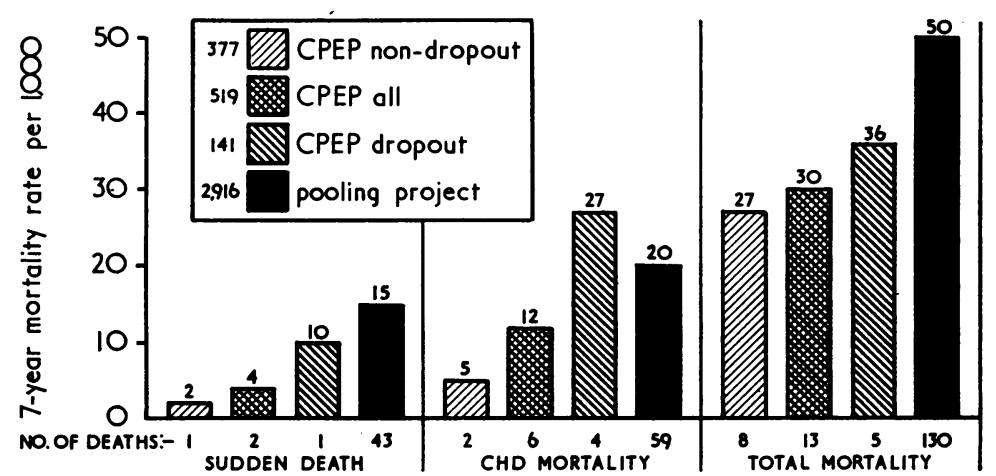


total mortality is 40.0 per cent lower than that of the Pooling Project men, and coronary heart disease mortality and sudden death rates are 40.0 and 73.3 per cent lower, respectively. No sizable difference is present for mortality from malignant neoplasms.

The generally favourable trend of the mortality rates for Programme men for all causes and coronary disease is further evident from the data on proportionate mortality. Thus, for the high risk men of the Pooling Project, coronary heart disease mortality rate at seven years was $40^{\circ} 0$ per cent of total mortality rate. In contrast, for the $\mathbf{3 7 7}$ active participants in the Coronary Prevention Evaluation Programme, the corresponding statistic is 18.5 per cent. Similarly, for the Pooling Project cohort, sudden death rate was 30.0 per cent of total mortality rate, whereas for the Coronary Prevention Evaluation Programme nondropouts it was only $7 \cdot 4$ per cent. These seeming benefits from long-term active participation in the Coronary Prevention Evaluation Programme are further suggested by the data showing that, for the 142 men dropping out of the programme, findings for these rates and ratios were generally similar to those of the Pooling Project men.

The mortality rates for the Coronary Prevention Evaluation Programme men were fur- ther compared with those for the individual cohorts of the Pooling Project. Seven-year cumulative mortality rates for coronary heart disease and sudden death in the total Coronary Prevention Evaluation Programme cohort of 519 men were lower than those of any of the individual comparison cohorts. Mortality rate for all causes for this Coronary Prevention Evaluation Programme cohort was lower than the rates for all but one of the Pooling Project cohorts. The contrast was similar and even more conspicuous for the cohort of 377 Coronary Prevention Evaluation Programme active participants (non-dropouts).

Further, the seven-year age-adjusted cumulative total mortality rates of 30 per thousand for all 519 Coronary Prevention Evaluation Programme men - and 27 per thousand for the 377 continuing active participants - are unusually low by any standard for men at this age. They are considerably lower than the rates for all U.S. men and all U.S. white men of this age (U.S. Public Health Service, 1969). Thus the 1967 age-adjusted mortality rate for U.S. white men age 40-59- lower in average age than the Coronary Prevention Evaluation Programme cohort over its seven years of follow-up - was 9.4 per 1,000 , or 65.8 per 1,000 over seven years (without adjustment to account for higher death rates with

TABLE I Detailed data on thirteen men, non-dropouts and dropouts, dying during the first seven years of follow-up: Coronary Prevention Evaluation Programme total cohort of 519 high-risk men as of 31 March 1970

\begin{tabular}{|c|c|c|c|c|c|c|}
\hline $\begin{array}{l}\text { Case } \\
\text { No. }\end{array}$ & $\begin{array}{l}\text { Age at } \\
\text { entry }\end{array}$ & $\begin{array}{l}\text { Risk factors } \\
\text { at entry }\end{array}$ & $\begin{array}{l}\text { Cigarette status } \\
\text { before death }\end{array}$ & $\begin{array}{l}\text { Months, dropout } \\
\text { to death }\end{array}$ & $\begin{array}{l}\text { Months, entry } \\
\text { to death }\end{array}$ & Cause of death \\
\hline \multicolumn{7}{|c|}{ Non-dropouts } \\
\hline 1045 & 59 & $\mathrm{C}+\mathrm{W}+\mathrm{S}$ & $\underset{\star}{\text { Current smoker }}$ & & 18 & Carcinoma of lung \\
\hline 3202 & 51 & $\begin{array}{l}\mathbf{C}+\mathbf{H}+\mathbb{W} \\
\mathbf{H}+\mathbf{W}\end{array}$ & Current smoker & E & 9 & Carcinoma of stomach \\
\hline $\begin{array}{l}5094 \\
6403\end{array}$ & 56 & $\begin{array}{l}H+W+S \\
H+W+S\end{array}$ & $\begin{array}{l}\text { Current smoker } \\
\text { Current smoker }\end{array}$ & - & 31 & $\begin{array}{l}\text { Carcinoma of pancreas } \\
\text { Homicide }\end{array}$ \\
\hline 6821 & $\begin{array}{l}41 \\
58\end{array}$ & $C+w+S$ & Current smoker & - & $\begin{array}{r}15 \\
7\end{array}$ & Carcinoma of liver \\
\hline 1020 & 53 & $\mathrm{C}+\mathrm{H}+\mathrm{W}+\mathrm{S}$ & Current smoker & - & 36 & Coronary heart disease \\
\hline $297 I$ & 47 & $\mathbf{C}+\mathbf{H}$ & Non-smoker & - & 19 & Coronary heart disease \\
\hline 6162 & 52 & $\mathbf{W}+\mathbf{H}$ & Non-smoker & 一 & 62 & $\begin{array}{l}\text { Subarachnoid } \\
\text { haemorrhage }\end{array}$ \\
\hline \multicolumn{7}{|c|}{ Dropouts } \\
\hline Or3I & 58 & $\mathbf{C}+\mathbf{H}+\mathbf{S}$ & No information & 12 & 33 & $\begin{array}{l}\text { Hypertensive } \\
\text { encephalopathy }\end{array}$ \\
\hline 1018 & $5 I$ & $\mathrm{C}_{2}+\mathrm{H}+\mathrm{W}+\mathrm{S}$ & Current smoker & 25 & 26 & Auto accident \\
\hline 1037 & 50 & $C_{2}+W+S$ & Current smoker & 19 & $4 \mathrm{I}$ & Coronary heart disease \\
\hline 2117 & 53 & $\mathbf{H}+\mathbf{W}+\mathbf{S}$ & Current smoker & 57 & 65 & Coronary heart disease \\
\hline 3109 & 40 & $C+\mathbb{W}+\mathbf{S}$ & No information & 8 & 29 & Coronary heart disease \\
\hline
\end{tabular}

C is hypercholesterolaemia, 260-324 mg./100 ml.

$\mathrm{C}_{2}$ is marked hypercholesterolaemia, $325 \mathrm{mg} . / 100 \mathrm{ml}$. or greater.

$W$ is overweight, relative weight of 1.15 or greater.

$S$ is any regular current use of cigarettes at entry.

$\mathrm{H}$ is hypertension, diastolic blood pressure $95 \mathrm{~mm}$. $\mathrm{Hg}$ or greater.

* Current cigar smoker. 

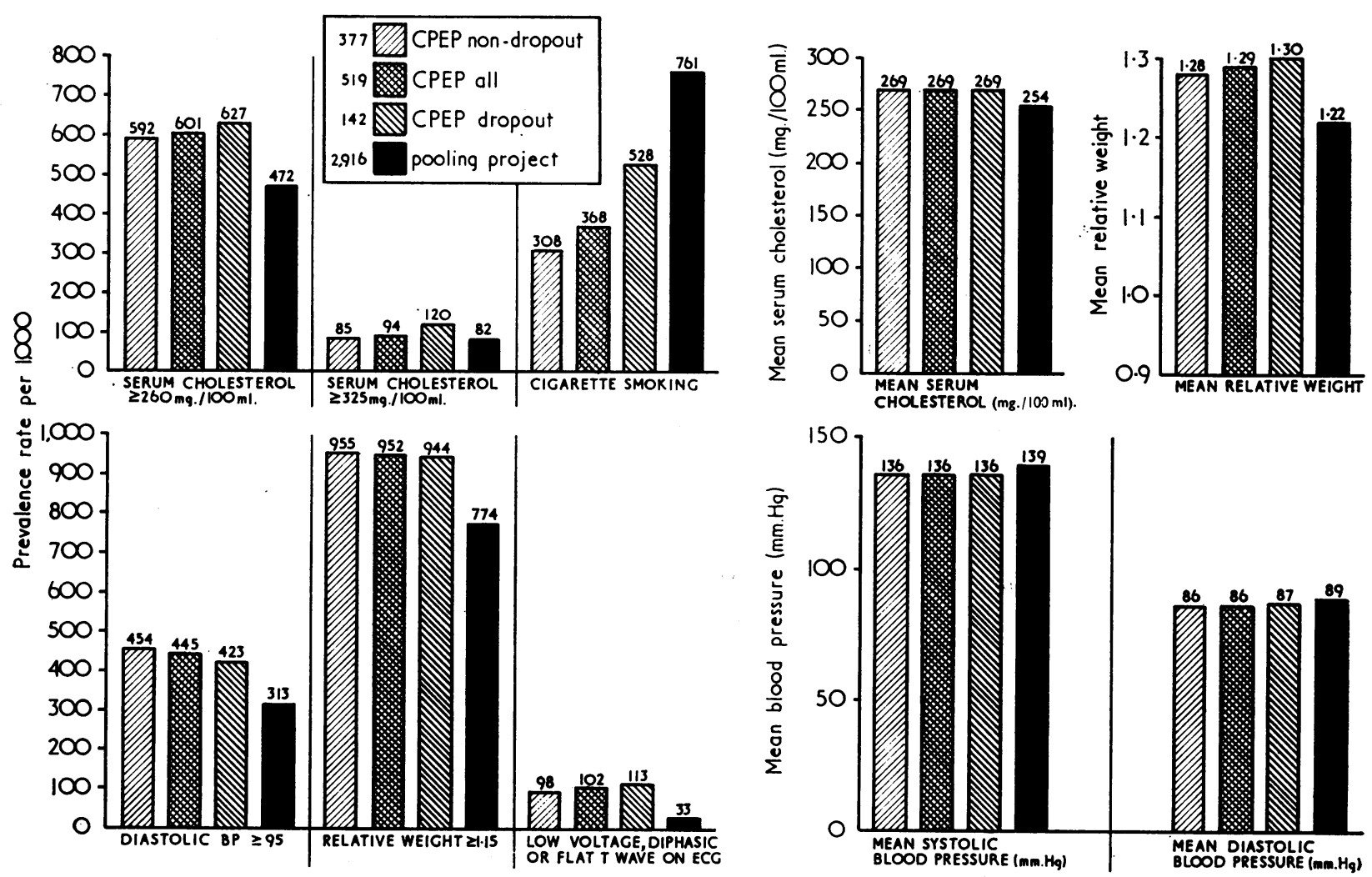

FIG. I3 Comparability in risk factor status at entry, Pooling Project and Coronary Prevention Evaluation Programme cohorts; prevalence rates and mean values for risk factors considered singly - that is, independently of each other.

greater age). Of greater importance, in terms of valid comparison, these rates are lower than those reported for male standard life insurance risks of like age (Lew, 1967). Thus for standard life insurance risks originally age 45 and 55 , ten-year mortality rates were 79 and 159 per 1,000 , respectively, or $54 \cdot 3$ and II I 3 per I,, 00 over seven years. Moreover, the rates for the Coronary Prevention Evaluation Programme men are almost identical with the calculated seven-year age-adjusted mortality rate from all causes for the approximately 20 per cent of men of the same age at greatly lower risk - that is, not high for either serum cholesterol, or blood pressure, or cigarette smoking - in the People's Gas Company study (see Fig. 5). Is this pure chance, or a true shift from higher to lower risk status of the Coronary Prevention Evaluation Programme active participants as a result of the prophylactic regimen?

Several additional analyses were done in an attempt further to evaluate this question. First, a detailed tabulation was obtained of the main information about the 13 men who died during the first years of the Coronary Prevention Evaluation Programme study (Table I). Four facts stand out. Firstly, II of the 13 decedents $(84.6 \%)$ had three or more coronary risk factors at entry, whereas only 39.3 per cent of the entire Coronary Prevention Evaluation Programme cohort manifested this pattern at entry, the remainder $(60.7 \%)$ having only two factors or severe hypercholesterolaemia only (Fig. I4).

Secondly, Io of the 13 men $(76.9 \%)$ were cigarette smokers at entry, so that there was a disproportionately high percentage of cigarette smokers among decedents compared with the overall Coronary Prevention Evaluation Programme cohort (36.8\%) (Fig. 13 and 14). Thirdly, these cigarette smokers who died all had two or more other risk factors at entry (rather than one only), whereas only 29. I per cent of the overall Coronary Prevention Evaluation Programme cohort showed this very high risk factor pattern at entry. 
Fourthly, at least 8 of the Io cigarette smokers, possibly as many as 12, were still smoking cigarettes at the time of death - that is, the programme had been ineffective in convincing them to quit this habit. Even though the number of decedents was small, these data strongly suggest that continued cigarette smoking is associated with very high risk of premature death for very coronary-prone men, and that other preventive measures are by themselves of limited value for them as long as they fail to give up cigarette smoking.

These detailed data highlighted an important problem, the comparability of the various groups being evaluated - first and foremost in regard to cigarette smoking status at entry but also in terms of other risk factors considered singly and in various combinations. Were the trends toward lower mortality rates of the total Coronary Prevention Evaluation Programme cohort and the Coronary Prevention Evaluation Programme non-dropouts due to lower risk at entry, especially in regard to cigarette smoking status at entry ? Extensive tabulations have recently been completed in an effort to clarify these problems. One of these involved a detailed analysis of the comparability of the cohorts in regard to risk factor status at entry. Prevalence rates per 1,000 were computed for each of the six risk factors individually - hypercholesterolaemia (260$324 \mathrm{mg} . / 100 \mathrm{ml}$.), overweight, hypertension, cigarette smoking, severe hypercholesterolaemia (325 mg./100 ml. or greater), fixed minor $T$ wave abnormalities on initial resting electrocardiogram, and for every possible combination of these. The findings are summarized in Fig. 13 and 14.

This matter of comparability of the Coronary Prevention Evaluation Programme and Pooling Project cohorts is a critically important one for this study. While identical criteria were utilized for their acceptance into the two cohorts of 519 and 2916 men, respectively, the possibility remains of disparate risks, based on detailed patterns of risk factor combinations (see Fig. 5). This is also a problem with respect to the two subgroups of Coronary Prevention Evaluation Programme men, nondropouts and dropouts. In fact, as long as the method of random assignment was not used in setting up these comparison groups, i.e. as long as they do not represent true experimental versus control groups in terms of optimal research design, this problem must be of the utmost concern.

Comparison of the total Pooling Project and Coronary Prevention Evaluation Programme cohorts of 2916 and 519 men respectively re-

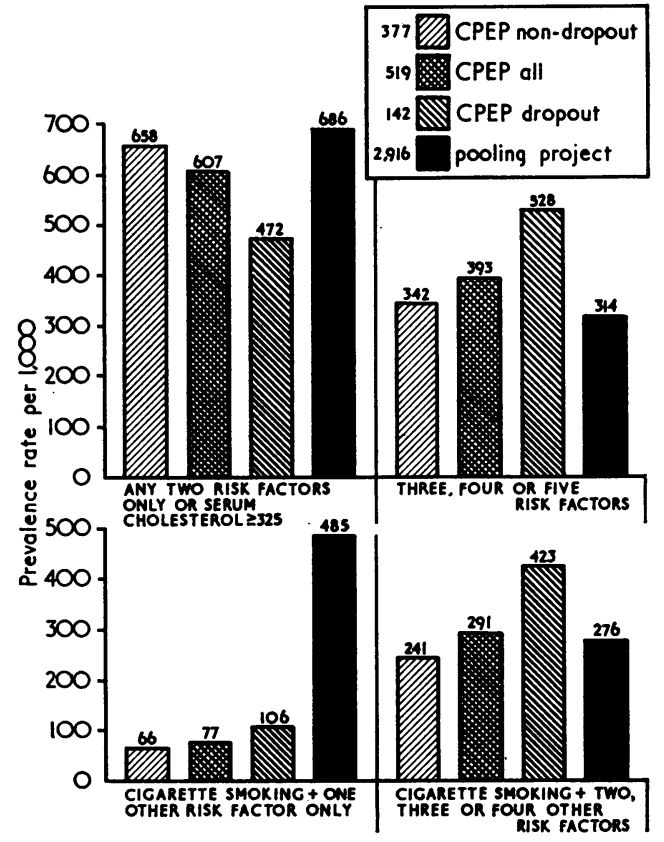

FIG. I4 Comparability in status at entry for combinations of risk factors (see Fig. 13), Pooling Project and Coronary Prevention Evaluation Programme cohorts.

veals the following: in regard to prevalence rates of each of the six risk factors considered separately, rates were considerably higher for the Coronary Prevention Evaluation Programme cohort for four of them (hypercholesterolaemia, hypertension, obesity, minor $\mathrm{T}$ wave abnormalities) compared with rates for the Pooling Project cohort (Fig. 13). The Pooling Project cohort had a far higher proportion of cigarette smokers than the total Coronary Prevention Evaluation Programme cohort. These Pooling Project men were predominantly cigarette smokers with one other risk factor only, whereas Coronary Prevention Evaluation Programme cigarette smokers were predominantly men with at least two or more other risk factors (Fig. 14). For such combinations of cigarette smoking plus two or more other factors, the two studies were generally well matched. With respect to all combinations of three or more risk factors, the cohort of 519 Coronary Prevention Evaluation Programme men generally had sizeably higher proportions of such very high risk men compared with the Pooling Project cohort.

When the Coronary Prevention Evaluation Programme continuing participants (377 nondropouts) were compared with the Pooling Project cohort, results similar to the foregoing 
TABLE 2 Seven-year cumulative mortality rates for non-cigarette smokers at entry, Pooling Project and Coronary Prevention Evaluation Programme groups

\begin{tabular}{|c|c|c|c|c|c|c|c|}
\hline \multirow{4}{*}{$\begin{array}{l}\text { Total mortality } \\
\text { Coronary heart disease } \\
\text { mortality }\end{array}$} & \multirow{2}{*}{\multicolumn{2}{|c|}{$\begin{array}{l}\begin{array}{l}\text { Pooling Project } \\
\text { non-cigarette smokers }\end{array} \\
697 \text { men }\end{array}$}} & \multicolumn{5}{|c|}{$\begin{array}{l}\text { Coronary Prevention Evaluation Programme } \\
\text { non-cigarette smokers }\end{array}$} \\
\hline & & & \multicolumn{2}{|c|}{ All: $328 \mathrm{men}$} & \multicolumn{2}{|c|}{ Non-dropout: 261 men } & \multirow{2}{*}{ Dropout: 67 men } \\
\hline & $14^{\star}$ & $24 \dagger \pm 7 \ddagger$ & 3 & $\mathbf{I} \pm 7$ & 3 & $18 \pm I I$ & \\
\hline & 4 & $6 \pm 3$ & I & $2 \pm 2$ & I & $3 \pm 3$ & 0 \\
\hline \multirow{2}{*}{$\begin{array}{l}\text { Sudden death } \\
\text { Malignant neoplasm } \\
\text { mortality }\end{array}$} & I & $I \pm I$ & $\mathbf{I}$ & $2 \pm 2$ & $\mathbf{I}$ & $3 \pm 3$ & 0 \\
\hline & 3 & $5 \pm 3$ & $\mathbf{I}$ & $2 \pm 2$ & $\mathbf{I}$ & $3 \pm 3$ & 0 \\
\hline
\end{tabular}

$\star$ Number of deaths.

$\dagger$ Age-adjusted rate per 1000 .

¥ Standard error of the rate.

were obtained (Fig. 13 and 14). As to the 142 Coronary Prevention Evaluation Programme dropouts, their prevalence rates were higher than those of the Pooling Project for five of the six risk factors considered singly, and for all but one of the very high risk (three, four, or five factor) combinations. Although, as already noted, a disproportionate number of Coronary Prevention Evaluation Programme dropouts were cigarette smokers, the prevalence rate of cigarette smoking at entry for this group was still below that of the Pooling Project cohort.

Finally, comparison of the Coronary Prevention Evaluation Programme non-dropout and dropout groups shows them to have generally similar prevalence rates for five of the six individual risk factors (Fig. 13 and 14 ). As already noted, prevalence rate of cigarette smoking was much higher in the dropouts than in the non-dropouts. Largely as a consequence of this phenomenon, the dropouts also showed higher prevalence rates for combinations of three, four, or five factors - that is, dropouts as a group tended to be higher risk at entry than non-dropouts.

These detailed data on comparability of groups and limitations therein, especially the differences in prevalence rates of cigarette smoking at entry, underscored the need for the additional data analyses presented in Tables 2 and 3, stratifying the groups based on cigarette smoking experience (see Table $\mathrm{r}$ ).

For non-cigarette smokers all mortality rates were low, and no clear-cut differences are apparent between the Pooling Project and Coronary Prevention Evaluation Programme (Table 2). While the trend of mortality from coronary heart disease and all causes favours the Coronary Prevention Evaluation Programme cohort, further assessment is needed based on longer follow-up - for example, the ten-year life table data. These findings will be forthcoming in the next years.

As to the cigarette smokers (Table 3), mortality rates were much higher overall than for non-cigarette smokers. Total mortality rate for Coronary Prevention Evaluation Programme men smoking cigarettes at entry was slightly higher overall than this rate for Pooling Project men. Coronary heart disease mortality rate was the same for the two groups. Sudden death rate was lower for Coronary Prevention Evaluation Programme than for Pooling Project men. For the II6 Coronary Prevention Evaluation Programme non-dropouts, both coronary heart disease and sudden death rates were lower than for the Pooling Project men, despite the fact that the former had a far higher proportion of very high risk men, men with cigarette smoking plus two or more other risk factors (see Fig. 14). The coronary heart disease mortality rate for these Coronary Prevention Evaluation Programme men was only one-third that of the Pooling Project men, and they had had no sudden deaths. Moreover, of these men remaining active in Coronary Prevention Evaluation Programme, all the deaths occurred among the 73 who did not quit cigarettes. Of the five deaths among these 73 continuing participants who did not quit cigarettes 3 were cancer deaths, of liver, lung, and pancreas, respectively, occurring relatively early in the study $(7,18$ and 31 months after entry, respectively) (Table I).

No deaths from cardiovascular or neoplastic causes occurred among the 43 Coronary Prevention Evaluation Programme men who stopped smoking cigarettes (Table 3). Obviously there is a problem here owing to the small size of groups. None the less, the data 
TABLE 3 Seven-year cumulative mortality rates for cigarette smokers at entry, Pooling Project and Coronary Prevention Evaluation Programme groups

\begin{tabular}{|c|c|c|c|c|c|c|c|c|c|c|c|}
\hline & \multirow{2}{*}{\multicolumn{2}{|c|}{$\begin{array}{l}\text { Pooling Project } \\
\text { cigarette smokers }\end{array}$}} & \multicolumn{9}{|c|}{ Coronary Prevention Evaluation Programme cigarette smokers } \\
\hline & & & \multicolumn{2}{|l|}{ All } & \multicolumn{5}{|c|}{ Non-dropout } & \multicolumn{2}{|c|}{ Dropout } \\
\hline & & & & & $A l$ & & $\underset{\text { cigarettes }}{\text { Quit }}$ & & $d_{t}$ not & & \\
\hline \multirow{5}{*}{$\begin{array}{l}\text { Total mortality } \\
\text { Coronary heart disease } \\
\text { mortality } \\
\text { Sudden death } \\
\text { Malignant neoplasm } \\
\text { mortality }\end{array}$} & 2219 & men & I9I & men & & 5 men & 43 men & & men & & men \\
\hline & $116^{\star}$ & $60 \dagger \pm 6 \ddagger$ & I0 & $73 \pm 22$ & 5 & $75 \pm 31$ & 0 & 5 & $150 \pm 52$ & 5 & $68 \pm 31$ \\
\hline & 55 & $25 \pm 4$ & 5 & $25 \pm 11$ & I & $8 \pm 8$ & 0 & I & $15 \pm 14$ & 4 & $45 \pm 22$ \\
\hline & 42 & $20 \pm 3$ & $\mathbf{I}$ & $6 \pm 5$ & 0 & $0^{-\infty}$ & o & 0 & 0 & I & $15 \pm 14$ \\
\hline & 26 & $14 \pm 3$ & 3 & $32 \pm 17$ & 3 & $60 \pm 29$ & 0 & 3 & $124 \pm 49$ & 0 & 0 \\
\hline
\end{tabular}

* Number of events.

$\dagger$ Rate/rooo age-adjusted.

$\ddagger$ Standard error of the rate.

certainly lend support to the concept that multifactor intervention to control several risk factors, including cigarette smoking as well as diet-dependent factors, is effective in preventing fatal myocardial infarction and coronary heart disease and in reducing mortality rate from all causes in highly coronaryprone middle-aged men. They are also consistent with the concept that low-saturated fat, low cholesterol, moderate calorie, and moderate polyunsaturated fat diets are without risk of excess morbidity and mortality from non-cardiovascular causes, specifically carcinomata (Dayton et al., 1969). These data further suggest that nutritional prophylactic measures may be of only limited value for very high risk cigarette smokers unless cessation of cigarette smoking is also accomplished as a key part of the multifactor prevention effort. Obviously all these inferences are tentative, since the mortality rates leading to them were based on a small group of men, randomization into experimental and control groups was not done, and the study remains to be completed.

\section{Conclusion: perspective}

All four 'first generation' studies on primary prevention of coronary heart disease - the New York Anti-Coronary Club, the Finnish mental hospital study, the Los Angeles Veterans Administration Domiciliary Center Study, and the Chicago Coronary Prevention Evaluation Programme - have presented findings indicating that change in living habits, particularly diet, and in the Chicago study cigarette smoking, is associated with decreased incidence or mortality, or both, from myocardial infarction and coronary heart disease. None of these studies was foolproof or perfect in design, methodology, or results. All were handicapped first and foremost by relatively small numbers, an unavoidable difficulty because of the small resources available when these investigations were undertaken in 1957-9. They had other problems as well - for example (for all but the Los Angeles study), that of proper randomly assigned control groups. Nevertheless, the similarities in findings are encouraging, and assume added significance in view of their consistency, as well as their agreement with expectation in terms of findings from clinical, pathological, animalexperimental, and descriptive epidemiological research. Certainly they cannot be dismissed or ignored.

Clearly 'second generation' trials are urgently needed, based on the earlier studies and learning from them. Several recent reports have emphasized the feasibility and necessity of proceeding with them (National Diet-Heart Study Research Group, I968; National Heart Institute, Diet-Heart Review Panel, 1969; Stamler et al., 1969c; White House Conference on Food, Nutrition and Health, 1970; Inter-Society Commission on Heart Disease Resources, 1970). Several are being planned - and one or two are already in progress (I. Frantz, personal communication, I970; G. Rose, personal communication, 1970; Oliver, 1970; Remington et al., 1969; S. Dayton and M. L. Pearce, personal communication, 1970; G. Tibblin, personal communication, 1970). However, no results will be forthcoming from them for years.

Practitioners of preventive and therapeutic medicine cannot and should not 'sit on their hands' in the interim, especially in view of 
the myocardial infarction and coronary heart disease epidemic confronting them. As the experiences of the Chicago Coronary Prevention Evaluation Programme, the New York Anti-Coronary Club, and the National DietHeart Study clearly show, large numbers of middle-aged men and their families are prepared to respond eagerly to effective professional leadership to combat this epidemic. Wisdom and responsibility call for widespread professional implementation now of reasonable, safe nutritional-hygienic approaches to primary prevention.

It is a pleasure to acknowledge the co-operation and support of Eric Oldberg, M.D., President, Chicago Board of Health, and chairman, Board of Directors, Chicago Health Research Foundation. It is also a pleasure to pay tribute to the entire staff of the Heart Disease Control Programme, Division of Adult Health and Aging, Chicago Health Department, and of the Chicago Health Research Foundation, aiding in this research, especially the author's senior colleagues in the long-term investigations presented here: David M. Berkson, M.D., Yolanda Hall, M.S., Howard A. Lindberg, M.D., Louise Mojonnier, Ph.D., Richard Shekelle, Ph.D., Rose Stamler, M.A.; also Howard Adler, Ph.D., Donald B. Cohen, M.D., Morton B. Epstein, Ph.D., George Farah, M.D., Jerome Frankel, M.D., S. Grujic, M.D., Louis Kolokoff, M.D., William MacIntyre, M.D., C. R. Paynter, M.D., Quentin D. Young, M.D., Stevie Catchings, Roberta Crawford, Nancy Dalton, Wanda Drake, Celene Epstein, Elise Fuente, W. Jackson, Dana King, Cecelia Kohorst, W. H. McAtee, Wilda A. Miller, Dorothy Moss, Joy Nelson, Gail Pacelli, Frances Petersen, Peggy Powell, Margie Shores, W. Sime, Betty Stevens, Eka Tomashewsky, June Wallace, T. Whipple, and Carol Zehnle. We are also grateful to P. Meier, Ph.D., of the Department of Statistics and the Biological Sciences Computation Center, University of Chicago. It is also a pleasure to express appreciation to the several Chicago organizations giving invaluable co-operation in this research effort, particularly the People's Gas, Light and Coke Company, its chairman, R. McDowell, and its medical director, Howard A. Lindberg, M.D.; the Newspaper Division of the Field Enterprises, particularly Wilbur Munnecke, formerly vicepresident and general manager, John G. Trezevant, vice-president and general manager, and Jacques Smith, M.D., medical director; the Medical Department of the American Oil Company, particularly Gilbeart Collings, M.D., and John Malia, M.D.; Armour and Company, particularly William Wood Prince, former chairman of the board; Illinois Bell Telephone Company and its medical director, Robert R. J. Hilker, M.D.; the Internal Revenue Service and its former medical director, Michael W. Langello, M.D.; and Mr. Donald J. Erickson, of Arthur Andersen and Company.

The author is most grateful to the principal investigators of the studies of Albany civil ser- vants, Chicago Western Electric Company studies, Framingham, Los Angeles civil servants, midwest railroad, and Minneapolis-St. Paul business men, and to the co-ordinators of the national co-operative Pooling Project for making data available from these major U.S. prospective studies for comparison with the findings of the Coronary Prevention Evaluation Programme. It is a pleasure to acknowledge the co-operation and aid of our colleagues in this endeavour, Drs. John M. Chapman, Thomas R. Dawber, Joseph T. Doyle, Frederick H. Epstein, William B. Kannel, Ancel Keys, Felix J. Moore, Oglesby Paul, and Henry L. Taylor.

This research has been supported by the American Heart Association, Chicago Heart Association, Best Foods Research Center, A Division of C.P.C. International, Inc., and the National Heart Institute, National Institutes of Health, United States Public Health Service.

\section{References}

American Public Health Association (1957). Measuring the risk of coronary heart disease in adult population groups: a symposium. American fournal of Public Health and the Nation's Health, 47, No. 4, Pt. 2.

Armstrong, M. L., Warner, E. D., and Connor, W. E. (1970). Regression of coronary atheromatosis in Rhesus monkeys. Circulation Research, 27, 59.

Chapman, J. M., and Massey, F. J., Jr. (1964). The interrelationship of serum cholesterol, hypertension, body weight, and risk of coronary disease. Results of the first ten years follow-up in the Los Angeles heart study. Fournal of Chronic Diseases, 17, 933.

Constantinides, P. (1965). Experimental Atherosclerosis. Elsevier, Amsterdam.

Coronary Drug Project Research Group (1970). Control of hyperlipidemia: 4. Progress in drug trials of secondary prevention, with particular reference to the Coronary Drug Project. In Atherosclerosis: Proceedings of the Second International Symposium, p. 586. Ed. by R. J. Jones. Springer-Verlag, New York, Heidelberg, and Berlin.

Cutler, S. J., and Ederer, F. (1958). Maximum utilization of the life table method in analyzing survival. fournal of Chronic Diseases, 8, 699.

Dawber, T. R., Kannel, W. B., and McNamara, P. M. (1964). The prediction of coronary heart disease. Transactions of the Association of Life Insurance Medical Directors of America, 47, 70.

Dayton, S., and Pearce, M. L. (1970). Diet and atherosclerosis. Lancet, I, 473.

- - - Hashimoto, S., Dixon, W. J., and Tomiyasu, U. (1969). A controlled clinical trial of a diet high in unsaturated fat, in preventing complications of atherosclerosis. Circulation, 39-40, Suppl. 2.

,,,--- Fakler, L. J., Hiscock, E., and Dixon, W. J. (I962). A controlled clinical trial of a diet high in unsaturated fat: preliminary observations. New England fournal of Medicine, 266, ro17.

Doyle, J. T. (1963). Risk factors in coronary heart disease. New York State fournal of Medicine, 63, 1317.

_., and Kinch, S. H. (1969). Coronary heart disease in the United States: some preliminary findings from the Pooling Project of the Council on Epidemiology of the American Heart Association. Presented at the 42nd Scientific Sessions, American Heart Association, November 14, 1969.

Fry, J. (1968). Acute myocardial infarction in British general practice. In Acute Myocardial Infarction, p. 
340. Ed. by D. G. Julian and M. F. Oliver. Livingstone, Edinburgh and London.

Herrick, J. B. (I912). Clinical features of sudden obstruction of the coronary arteries. Fournal of the American Medical Association, 59, 2015.

Inter-Society Commission on Heart Disease Resources (1970). The primary prevention of the atherosclerotic diseases. Circulation, 62, A-55.

Jolliffe, N., Rinzler, S. H., and Archer, M. (1962). Prudent reducing diet: effect on serum cholesterol. Archives of Internal Medicine, 109, 566.

Kannel, W., and Doyle, J. T. (197I). Epidemiology of ischaemic heart disease - risk factors: ten year findings on 8,600 American men - Pooling Project, Council on Epidemiology, American Heart Association. In the press.

Katz, L. N., and Stamler, J. (1953). Experimental Atherosclerosis, p. 43. C. C. Thomas, Springfield, Illinois.

, - - and Pick, R. (1958). Nutrition and Atherosclerosis. Lea and Febiger, Philadelphia

Keys, A. (1970). Coronary heart disease in seven countries. Circulation, 41-42, Suppl. I.

, Taylor, H. L., Blackburn, H., Brozek, J., Anderson, J. T., and Simonson, E. (1963). Coronary heart disease among Minnesota business and professional men followed fifteen years. Circulation, 28, 381.

Lew, E. A. (1967). Blood pressure and mortality: life insurance experience. In The Epidemiology of Hypertension, p. 392. Ed. by J. Stamler, R. Stamler, and T. N. Pullman. Grune and Stratton, New York.

Lown, B., Klein, M. D., and Hershberg, P. I. (1969). Coronary and precoronary care. American fournal of Medicine, 46, 705 .

McGill, H. C., Jr. (1968). The Geographic Pathology of Atherosclerosis. Williams and Wilkins, Baltimore.

Moore, F. E. (1969). Some preliminary findings from the Pooling Project of the Council on Epidemiology, American Heart Association. Paper Presented at the Conference on Cardiovascular Disease Epidemiology, Council on Epidemiology, American Heart Association, 3-4 March 1969, New Orleans.

Moriyama, I. M., Stamler, J., and Krueger, D. E. (1971). The Major Cardiovascular Diseases: An Epidemiological Analysis. American Public Health Association, New York. In the press.

Mortality Statistics - Cardiovascular Diseases, Annual Statistics, 1955-1964 by Age and Sex (1967). Epidemiological and Vital Statistics Report, 20, 535.

Moss, A. J., Wynar, B., and Goldstein, S. (I969). Delay in hospitalization during the acute coronary period. American fournal of Cardiology, 24, 659.

National Diet-Heart Study Research Group (1968). The national diet-heart study final report. Circulation, 37-38, Suppl. I.

National Heart Institute, Diet-Heart Review Panel (1969). Mass field trials of the diet-heart question: their significance, timeliness, feasibility and applicability. American Heart Association Monographs 28.

Oliver, M. (1970). Control of hyperlipidemia: the use of drugs in the primary prevention of ischemic heart disease. In Atherosclerosis: Proceedings of the Second International Symposium, p. 582. Ed. by R. J. Jones. Springer-Verlag, New York, Heidelberg, and Berlin.

Pantridge, F. (1968). Flying Squad services. In Acute Myocardial Infarction, p.316. Ed. by D. G. Julian and M. F. Oliver. Livingstone, Edinburgh, and London.

Paul, O., Lepper, M. H., Phelan, W. H., Dupertuis, G. W., MacMillan, A., McKean, H., and Park, H. (1963). A longitudinal study of coronary heart disease. Circulation, 28, 20.

Remington, R., Stamler, J., Taylor, H., et al. (1969). Multifactor CHD Prevention Study: grant applica- tion submitted to the National Heart and Lung Institute. (Unpublished.)

Rinzler, S. H. (1968). Primary prevention of coronary heart disease by diet. Bulletin of the New York Academy of Medicine, 44, 936.

Stamler, J. (1960). Current status of the dietary prevention and treatment of atherosclerotic coronary heart disease. Progress in Cardiovascular Disease, 3,56 . (1967). Lectures on Preventive Cardiology. Grune and Stratton, New York.

- (1969a). Regional differences in mortality, prevalence and incidence of ischaemic heart disease. In Boerhaave Course on Ischaemic Heart Disease, 1969, Leiden. Ed. by H. A. Snellen. Springer-Verlag, New York, Heidelberg, and Berlin. In press.

- (I969b). Prevention of atherosclerotic coronary heart disease. In Modern Trends in Cardiology, 2, p. 88. Ed. by A. M. Jones. Butterworths, London. , Berkson, D. M., Cohen, D. B., Epstein, M. B., Frankel, J. J., Hall, Y., Lindberg, H. A., Mojonnier, L., Shekelle, R. B., Soyugenc, R., and Stamler, R. (1969b). Prevention of atherosclerotic coronary heart disease by change of diet and mode of life. In Boerhaave Course on Ischaemic Heart Disease, 1969, Leiden. Ed. by H. A. Snellen. Springer-Verlag New York, Heidelberg, and Berlin. In press.

-, Epstein, F. H., Green, J. G., and Keys, A. (I969). Mass Field Trials on the Prevention of Coronary Heart Disease: Perspectives and Tasks. Report of an International Working Meeting, Makarska, Yugoslavia, Sept. 19-24, 1968. Privately printed, Chicago, Illinois.

-, Schoenberger, J. A., Lindberg, H. A., Shekelle, R., Stoker, J. M., Epstein, M. B., deBoer, L., Stamler, R., Restivo, R., Gray, D., and Cain, W. (1969a). Detection of susceptibility to coronary disease. Bulletin of the New York Academy of Medicine, 45, 1306.

Taylor, C. B., Patton, D. E., and Cox, G. E. (1963) Atherosclerosis in Rhesus monkeys. VI. Fatal myocardial infarction in a monkey fed fat and cholesterol. Archives of Pathology, 76, 404.

Taylor, H. L., Klepetar, E., Keys, A., Parlin, W. Blackburn, H., and Puchner, T. (I962). Death rates among physically active and sedentary employees of the railroad industry. American fournal of Public Health and the Nation's Health, 52, 1697.

Turpeinen, O., Miettinen, M., Karvonen, M. J., Roine, P., Pekkarinen, M., Lehtosuo, E. J., and Alivirta, P. (1968). Dietary prevention of coronary heart disease: long-term experiment. I. Observations on male subjects. American fournal of Clinical Nutrition, 21, 255.

, Roine, P., Pekkarinen, M., Karvonen, M. J., Rautanen, Y., Runeberg, J., and Alivirta, P. (I960). Effect on serum-cholesterol level of replacement of dietary milk fat by soy bean oil. Lancet, $1,196$.

United States, Public Health Service (1969). Vital Statistics of the United States, 1967, Vol. II, Part A, Mortality. U.S. Department of Health, Education and Welfare Public Health Service, Washington, D.C.

White House Conference on Food, Nutrition and Health (1970). Final Report to the President. Washington, D.C.

White, P. D. (1944). Heart Disease, 3rd ed., p. 478. Macmillan, New York.

Wissler, R. W. (1968). Recent progress in studies of experimental primate atherosclerosis. Progress in Biochemical Pharmacology, 4, 378.

Zelis, R., Mason, D. T., Braunwald, E., and Levy, R. I. (1970). Effects of hyperlipoproteinemias and their treatment on the peripheral circulation. fournal of Clinical Investigation, 49, ro07. 